\title{
EVOLUTION OF THE INFECTION OF THE SARS-COV-2 IN ITALY, GENERAL EPIDEMIOLOGICAL RESULTS AND NEW STRADEGIC HYPOTHESES RELATED TO TERRESTRIAL CLIMATE
}

\section{Author: Daniele Cataldi ${ }^{1}$}

Doctor in Nursing Sciences - Independent Researcher ${ }^{1}$

daniele77c@hotmail.it ${ }^{1}$

DOI: 10.26821/IJSRC.9.8.2021.9822

\begin{abstract}
What do we know about the progress of Covid-19 infection? In this study the data coming from the Italian pandemic trend are analyzed, and discussed with the European and World Trend of the same infection. What are the factors that could influence the distribution of this virus? In this context of research it is possible to understand what may have influenced its spread and what may have helped contain it? This study has tried to advance hypotheses in relation to such questions, hypotheses based on official and indisputable scientific data.
\end{abstract}

Keywords: SARS-CoV-2, COVID-19, Italy,

Pandemic evolution, Climate.

\section{PREMISE}

Coronavirus (VOC) are a wide family of respiratory viruses that can cause mild to moderate diseases, from the common cold to respiratory syndromes such as Mers (Middle East Respiratory Syndrome, Middle East Respiratory Syndrome) and SARS (severe acute respiratory syndrome, Severe acute respiratory syndrome).

They are called so for crown-shaped tips that are present on their surface [13].

Human coronavirus known to today, common around the world, are seven, some identified several years ago (the first half of the sixties) and some identified in the new millennium.
Common human coronavirus:

- 229E (coronavirus alpha)

- NL63 (coronavirus alpha).

- OC43 (coronavirus beta).

HKU1 (coronavirus beta)

Other human coronavirus:

- MERS-CoV (The Coronavirus beta that causes the Middle East Respiratory Syndrome).

- SARS-CoV (The Coronavirus beta that causes the Severe Acute Respiratory Syndrome).

- SARS-CoV-2 (The Coronavirus causing the COVID-19) [13].

The Coronavirus 2 from severe acute respiratory syndrome, abbreviated in SARS-COV-2 (severe acute respiratory syndrome coronavirus 2) [2] [3], previously appointed new coronavirus of 2019 (2019-nCoV [5]), is a viral strain of the coronavirus species related to the Sars belonging to the genus betacoronavirus (coronaviridae family), subgenere sarbecovirus, discovered around the end of 2019; This is the seventh coronavirus recognized capable of infecting human beings [3].

The official name given by the OMS - World Health Organization to the syndrome caused by the virus is COVID-19 (COronaVIrus Disease-2019) [4].

The virus was genuinely sequenced after a nucleic acid test carried out on a sample taken from a patient struck by a pneumonia, whose cause was not known, at the 
beginning of the pandemic of 2019-2021 in Wuhan, in China [6][7][8].

Towards the end of January 2020 the virus spread to Bangkok (Thailand), Tokyo (Japan), Seoul (South Korea), China, Taiwan, Hong Kong, Macao, Malaysia, Japan, United States, Vietnam, Singapore, France, Germany, Australia, Canada, Nepal, Cambodia, Sri Lanka, Italy, United Arab Emirates, United Kingdom, Brazil, Russia and Spain [9].

Although the virus transmission methods were not yet clear, it was confirmed that it is able to go from person to person.

A public health official in the state of Washington in the United States noted that coronavirus are broadcast mainly "through a close contact with another individual, in particular to be treated and sneezing on someone else who is within a radius of about 1-2 meters from that person" [10].

Although respiratory viruses are usually transmitted when the sick subject also has symptoms, it would seem that the SARS-COV-2 can spread even during a close contact with an asymptomatic patient [11].

It is estimated that the basic reproduction number of virus transmission from person to person is between 1.4 and 3.8 .

This value indicates the number of other people to which a newly infected patient can transmit the

\section{0 - METHOD}

The study of statistical data relating to the infection from SARS-COV-2, registered in Italy, is essentially based on data from certain and officers sources, which is that of Italian national civil protection (Civil Protection Department) [1], that during the pandemic, for example also curated also the distribution of PPE or individual protection devices, in the Hospitals of the SSN - National Health Service and those of the private but affiliated, accredited and classified. In addition to this data source, the study considered the data from the European Center for Disease Prevention and Control An Agency of the European Union (both for European and global data).

Important official sources, through which it was possible to provide objective indications on the results of the Italian and European pandemic crisis.

\section{2 - Data Analysis:}

The first part of the data analyzed are those coming disease. According to reportedly, the new Coronavirus was so far able to transmit to a chain up to a maximum of four people [12].

As is obvious, therefore the transmission of the virus takes place mainly by air, or by contact with our mucous membranes.

It is therefore a matter of limiting this possibility of contact and entry into our body, using Individual Protection Devices (IPD), as well as the use of lifestyles adapted to this problematic (washing and disinfection of the hands, frequent disinfection of the surfaces In contact with the persons on which the virus can settle, use of specific antiseptics in living, work or hospital environments, etc.), adopting behaviors that can go to limit the possibility of contagion even with social spacing; but the mitigation of the diffusion of this new virus, also depends on other factors, which until today were not considered by health policies at non-Italian but also global level policies.

The transmission of this infection seems to be homogeneous within the European continent, because cases of infection have presented the same trend with respect to the temporal context in which they were observed. In the next chapters these data will be analyzed and we will try to provide hypothetical explanations with respect to such pandemic behavior.

from the Department of Italian Civil Protection, data relating to COVID-19 infections, attested by specific laboratory tests. In this case the scrutinized data is daily and attest to the progress of the infection from COVID-19, throughout the period considered (from 24 February 2020 to 5 June 2021).

The following is the series of graphs, divided by Italian region, as well as by general national trend, the number of infections from SARS-COV-2 registered daily in the period considered in this study.

The data was extrapolated from the Italian official source, or the Department of Civil Protection, appointed by the Count Government and by the Draghi government to verify the daily trend of contagations, as well as the number of deaths and that of patients resigned / healed.

These data were also counted by region, to understand how the virus was spreading on the Italian peninsula. 
It is evident as the trend of each Italian region, follow what is a national and international trend of cases of daily infection.
As we will see later, this particular characteristics requires considering precise hypotheses, which we will soon analyze.

Figure 1 - National trend - 2020-2021

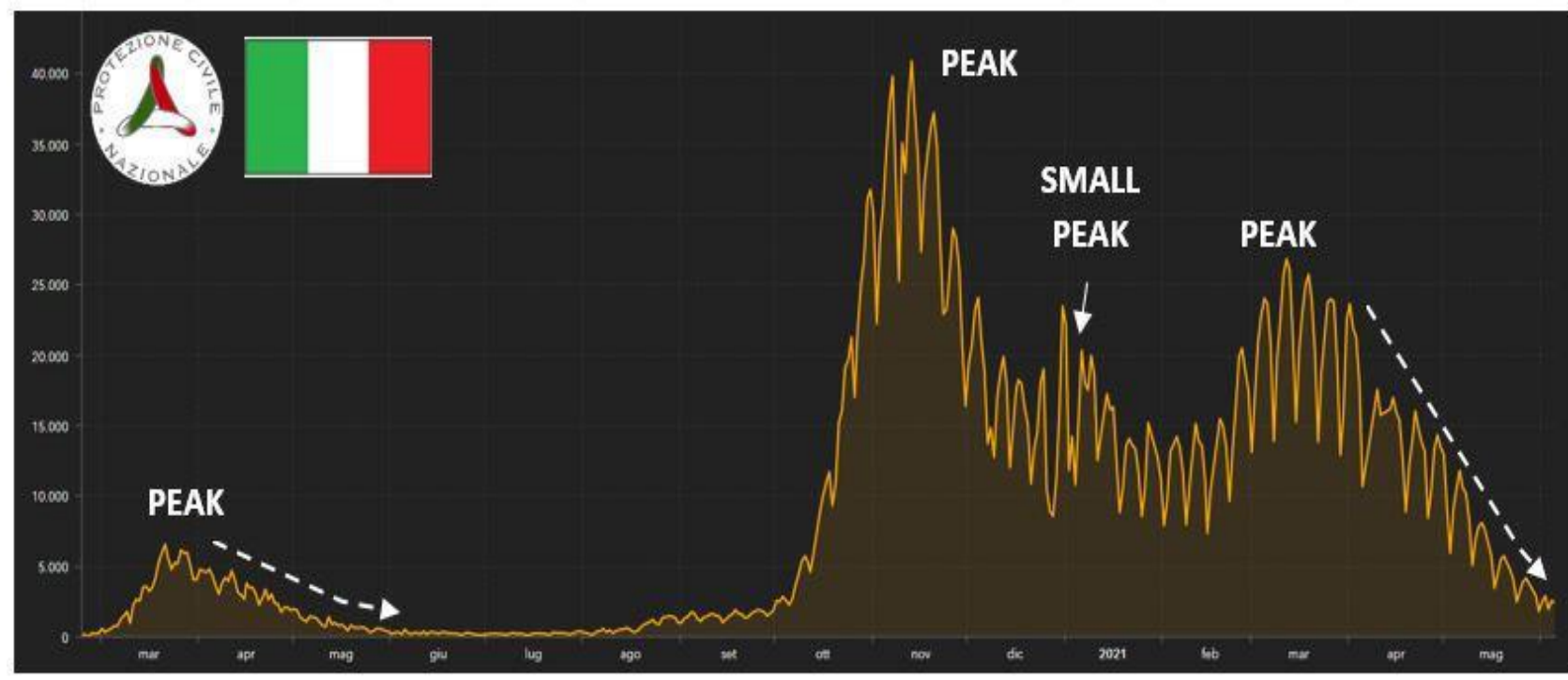

Fig. 1 - Chart showing the evolution of the infection of the SARS-CoV-2, from 24 February 2020 to 5 June 2021. National trend (Italy). On the axis of the ordered, the number of infected are visible, while the temporal context in months is visible on the abscissa axis. Credits: Department of Civil Protection - Presidency of the Council of Ministers.

Figure 2 - Trend of the Abruzzo Region - 2020-2021 (t)

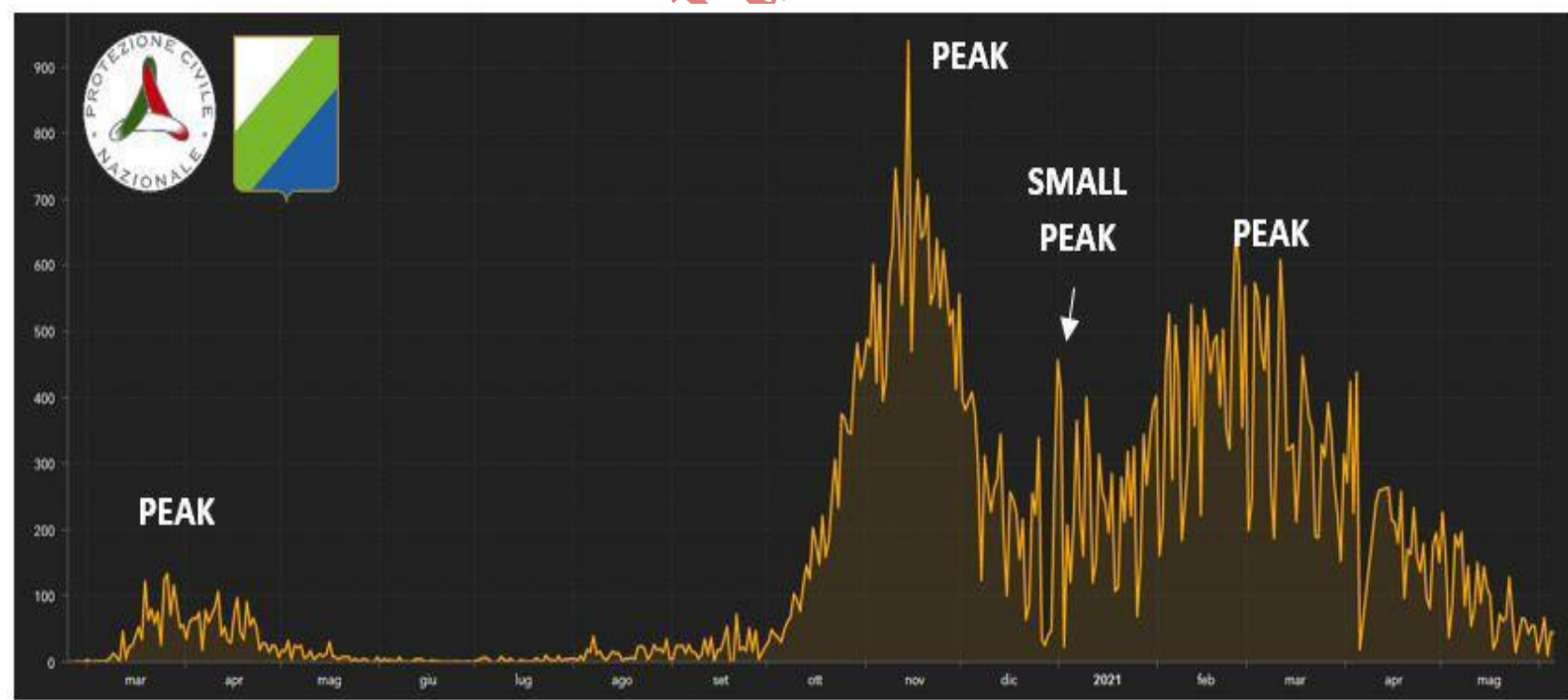

Fig. 2 - Graph showing the evolution of SARS-CoV-2 infection, from 24 February 2020 to 5 June 2021. Regional trend (Abruzzo). On the axis of the ordered, the number of infected are visible, while the temporal context in months is visible on the abscissa axis. Credits: Department of Civil Protection - Presidency of the Council of Ministers. 
Figure 3 - Trend of the Basilicata Region - 2020-2021

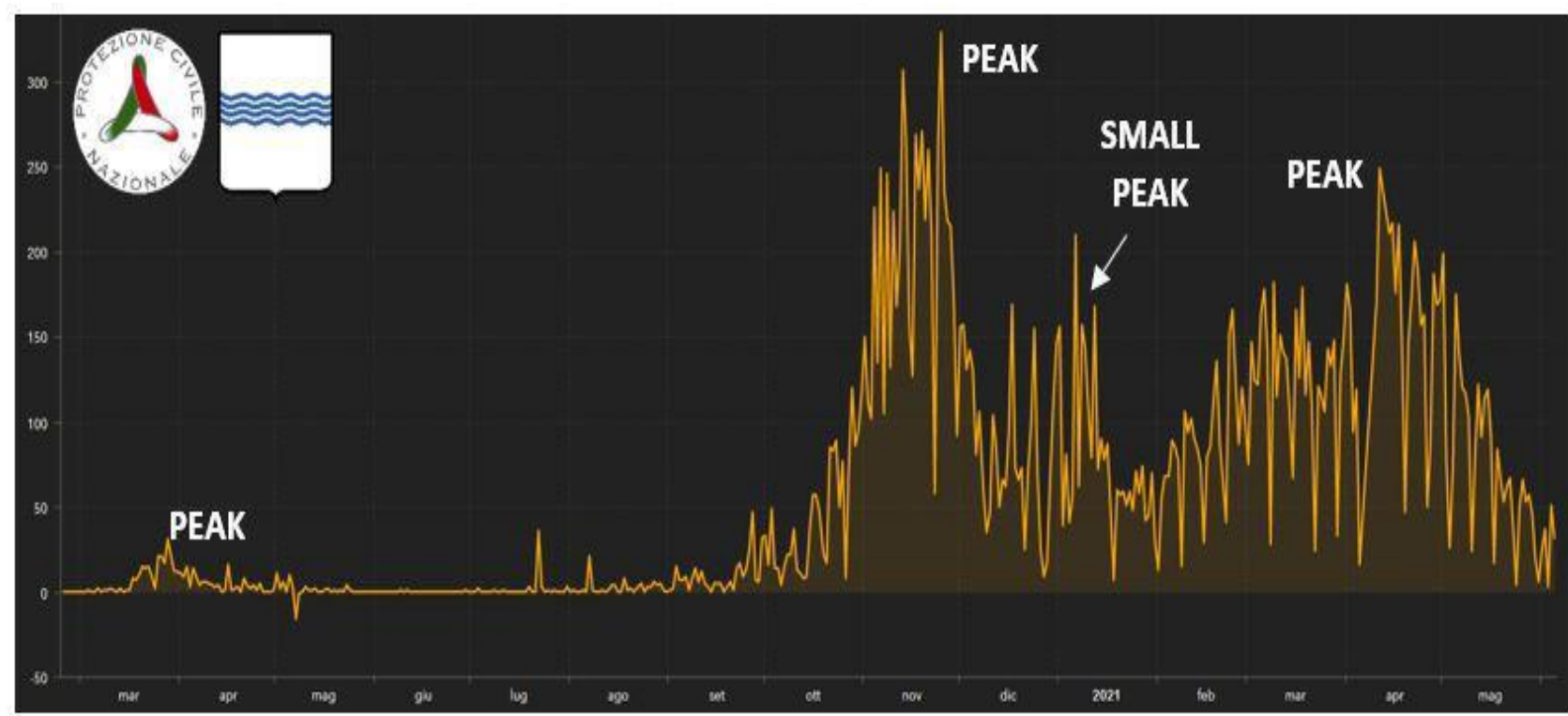

Fig. 3 - Graph showing the evolution of the SARS-CoV-2 infection, from 24 February 2020 to 5 June 2021. Regional trend (Basilicata). On the axis of the ordered, the number of infected are visible, while the temporal context in months is visible on the abscissa axis. Credits: Department of Civil Protection - Presidency of the Council of Ministers.

Figure 4 - Trend of the Calabria Region - 2020-2021 a 1

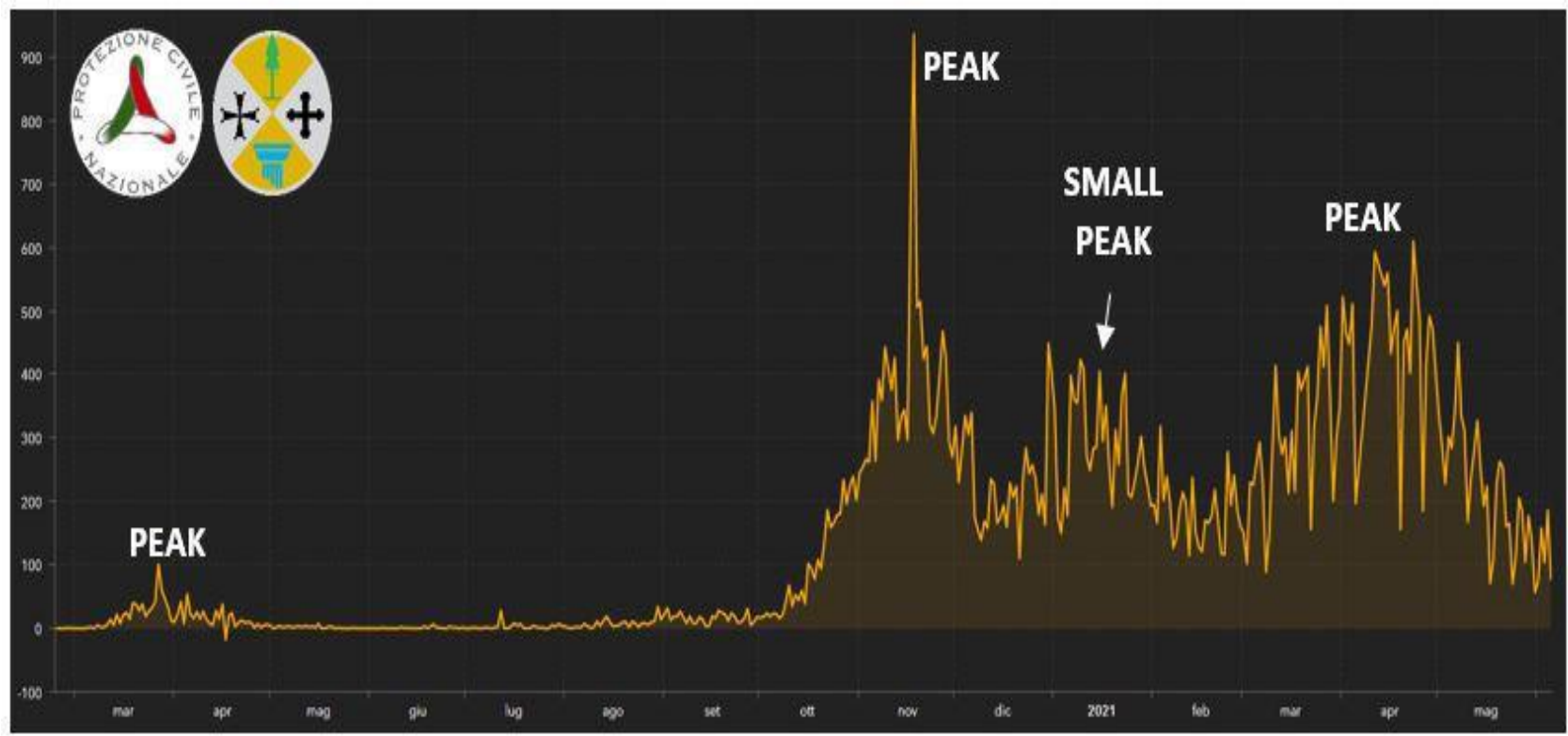

Fig. 4 - Graph showing the evolution of the SARS-CoV-2 infection, from 24 February 2020 to 5 June 2021. Regional trend (Calabria). On the axis of the ordered, the number of infected are visible, while the temporal context in months is visible on the Abscissa axis. Credits: Department of Civil Protection - Presidency of the Council of Ministers. 
Figure 5 - Trend in the Campania Region - 2020-2021

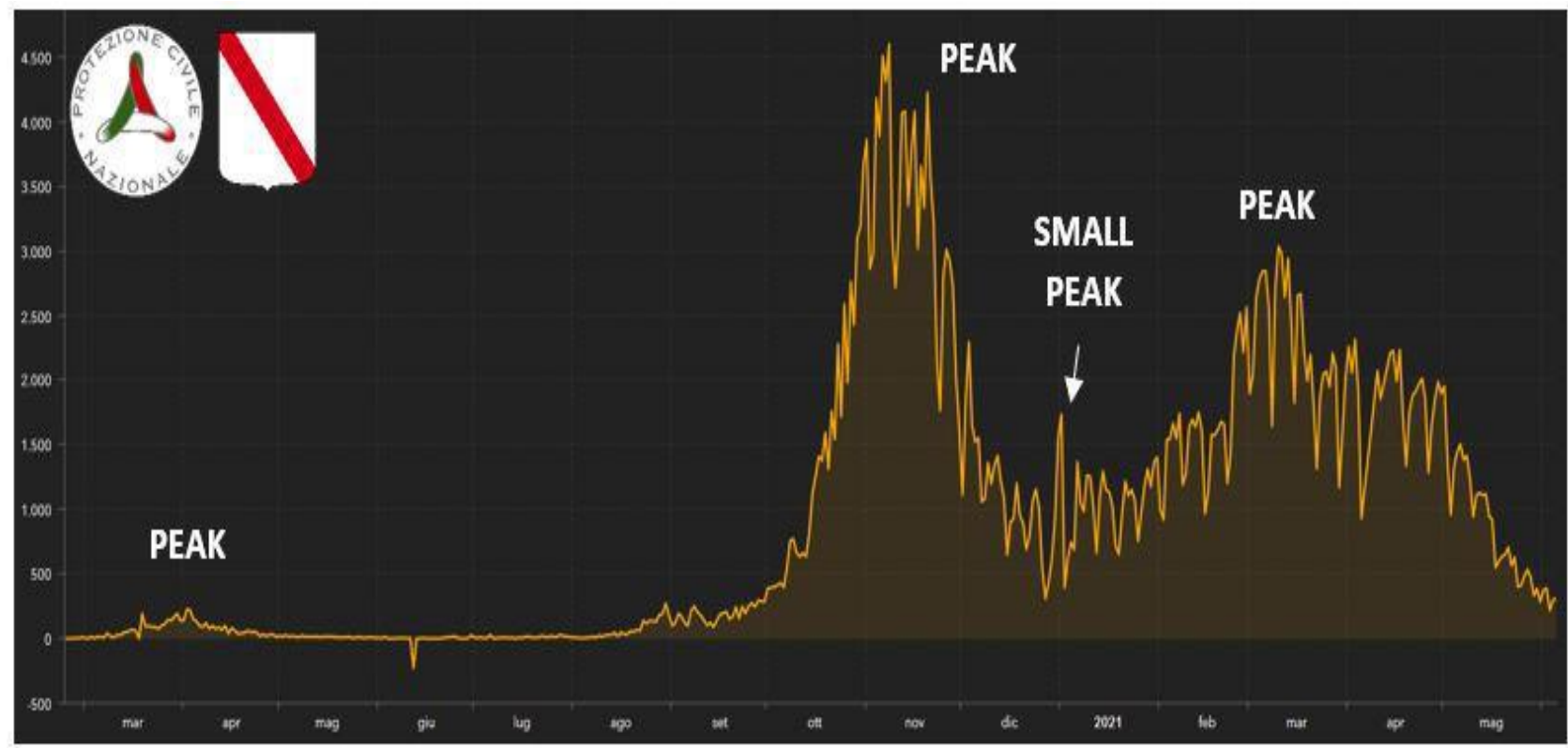

Fig. 5 - Graph showing the evolution of the infection of the SARS-CoV-2, from 24 February 2020 to 5 June 2021. Regional trend (Campania). On the axis of the ordered, the number of infected are visible, while the temporal context in months is visible on the abscissa axis. Credits: Department of Civil Protection - Presidency of the Council of Ministers.

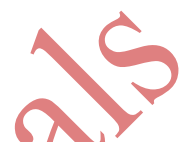

Figure 6 - Trend in the Emilia-Romagna Region - 2020-2021

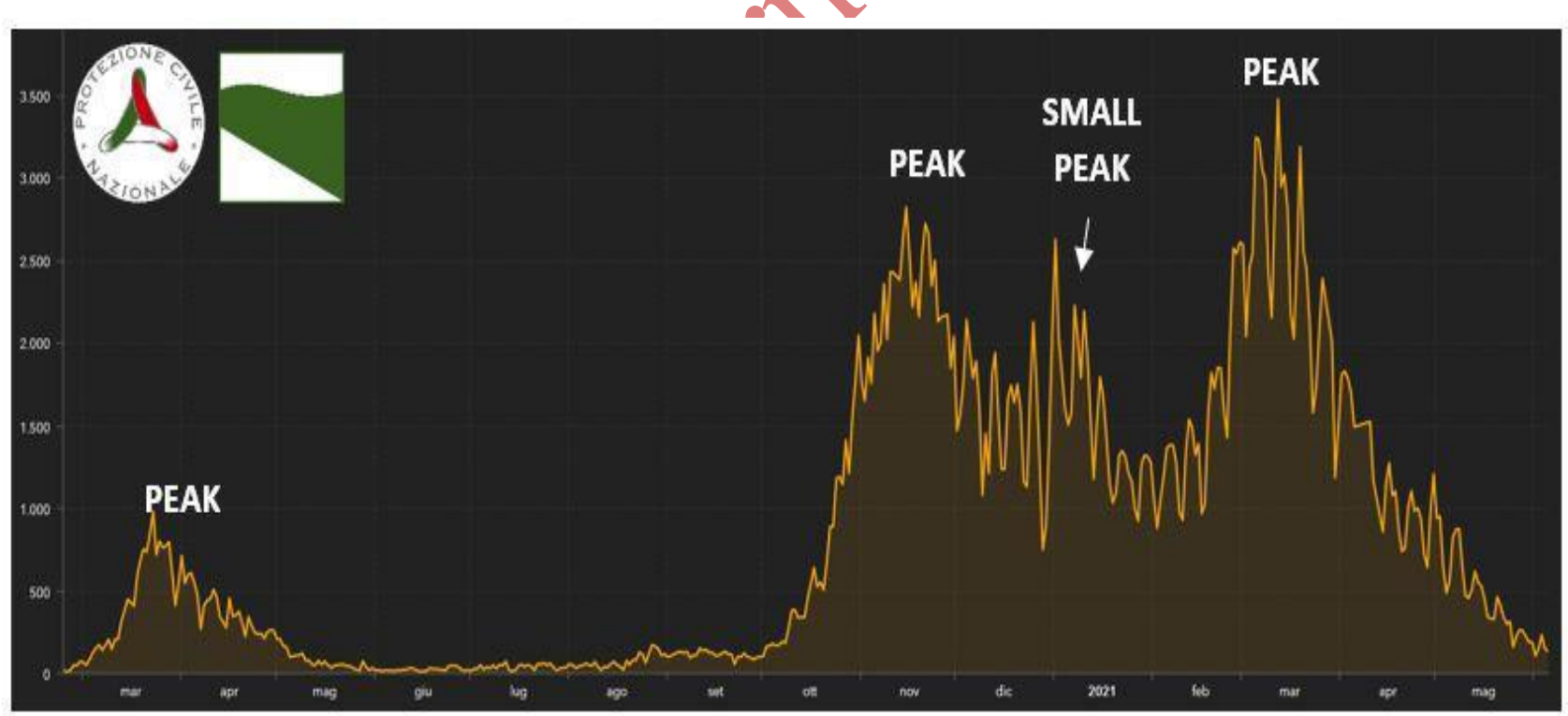

Fig. 6 - Graph showing the evolution of the infection of the SARS-CoV-2, from 24 February 2020 to 5 June 2021. Regional trend (Emilia-Romagna). On the axis of the ordered, the number of infected are visible, while the temporal context in months is visible on the abscissa axis. Credits: Department of Civil Protection - Presidency of the Council of Ministers. 
Figure 7 - Trend in the Friuli Venezia Giulia Region - 2020-2021

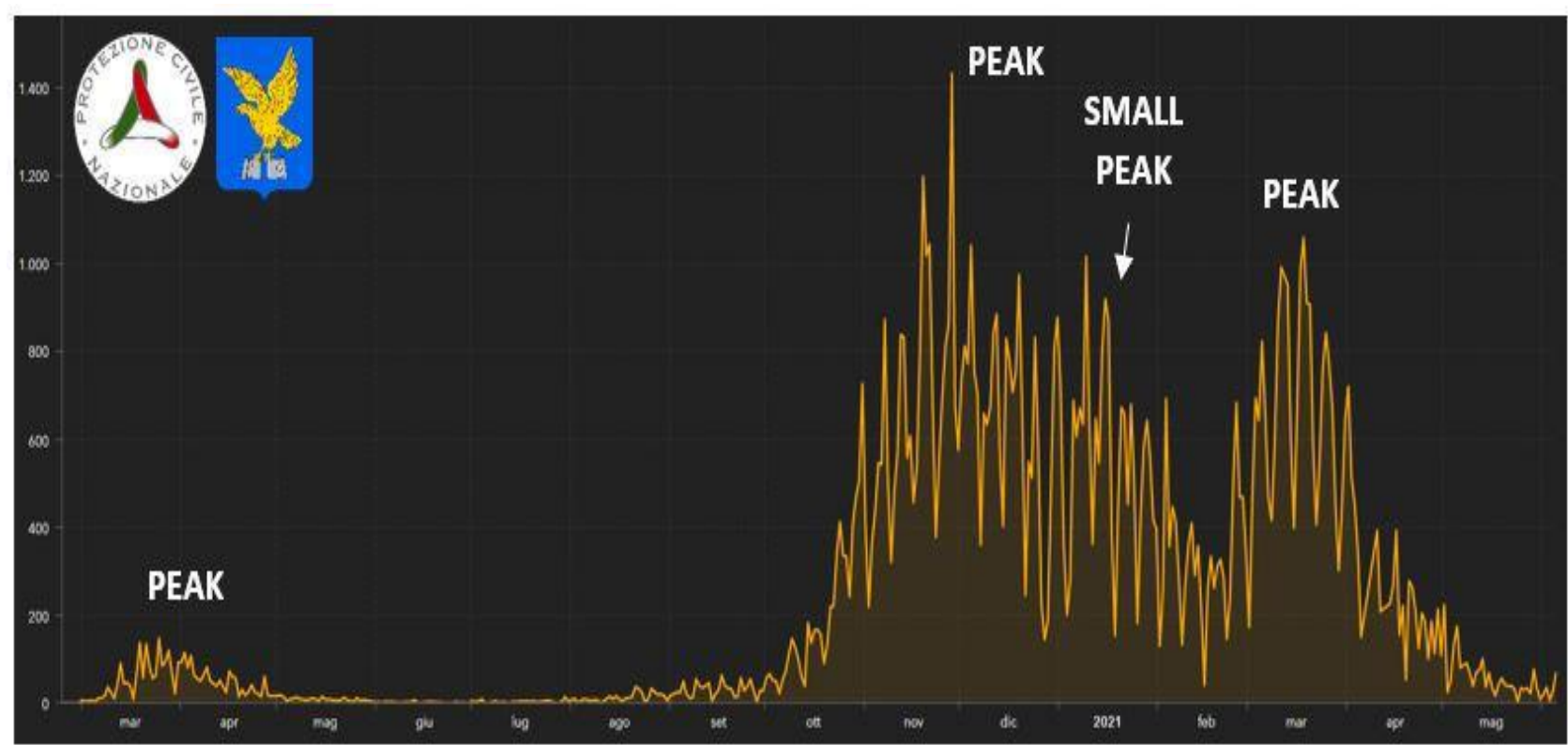

Fig. 7 - Graph showing the evolution of the SARS-CoV-2 infection, from 24 February 2020 to 5 June 2021.

Regional trend (Friuli Venezia Giulia). On the axis of the ordered, the number of infected are visible, while the temporal context in months is visible on the abscissa axis. Credits: Department of Civil Protection - Presidency of the Council of Ministers.

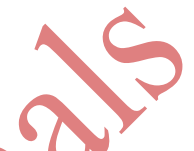

Figure 8 - Trend in the Lazio Region - 2020-2021 ap $y$

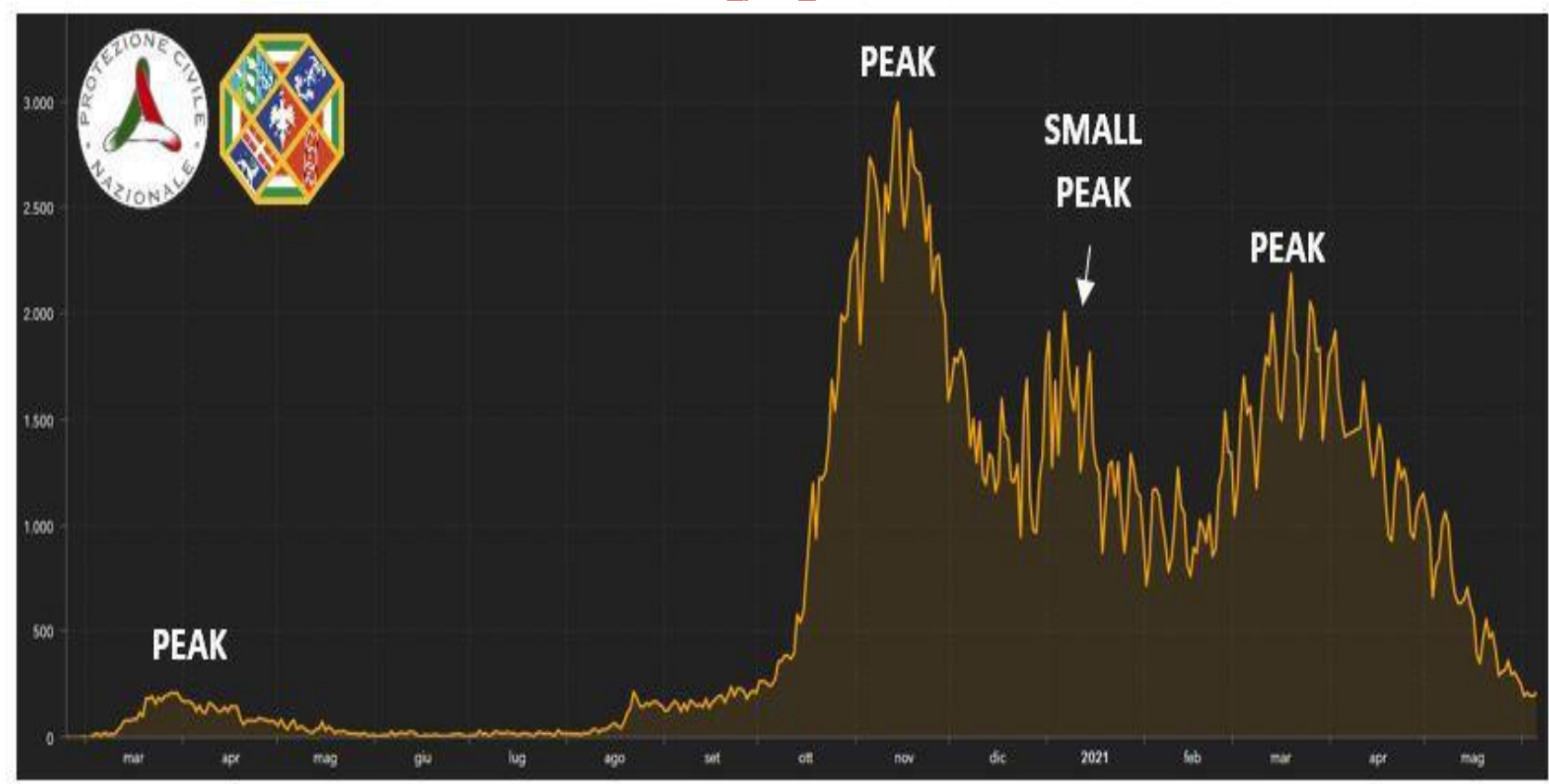

Fig. 8 - Graph showing the evolution of the infection of the SARS-CoV-2, from 24 February 2020 to 5 June 2021. Regional trend (Lazio). On the axis of the ordered, the number of infected are visible, while the temporal context in months is visible on the abscissa axis. Credits: Department of Civil Protection - Presidency of the Council of Ministers. 
Figure 9 - Trend of the Liguria Region - 2020-2021

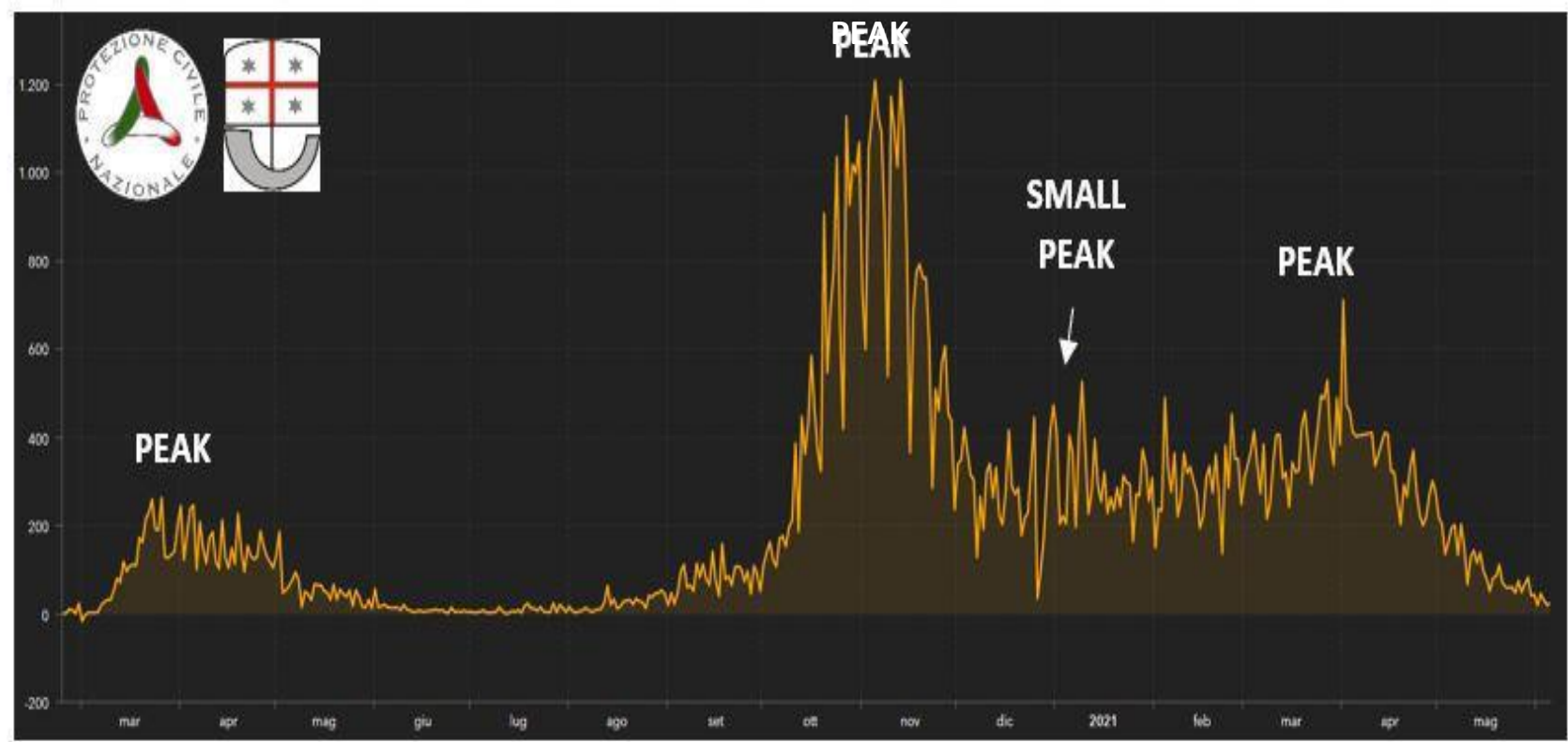

Fig. 9 - Graph showing the evolution of the SARS-CoV-2 infection, from 24 February 2020 to 5 June 2021. Regional trend (Liguria). On the axis of the ordered, the number of infected are visible, while the temporal context in months is visible on the abscissa axis. Credits: Department of Civil Protection - Presidency of the Council of Ministers.

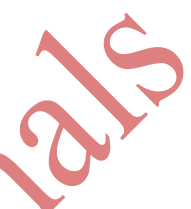

Figure 10 - Trend of the Lombardy Region - 2020-2021

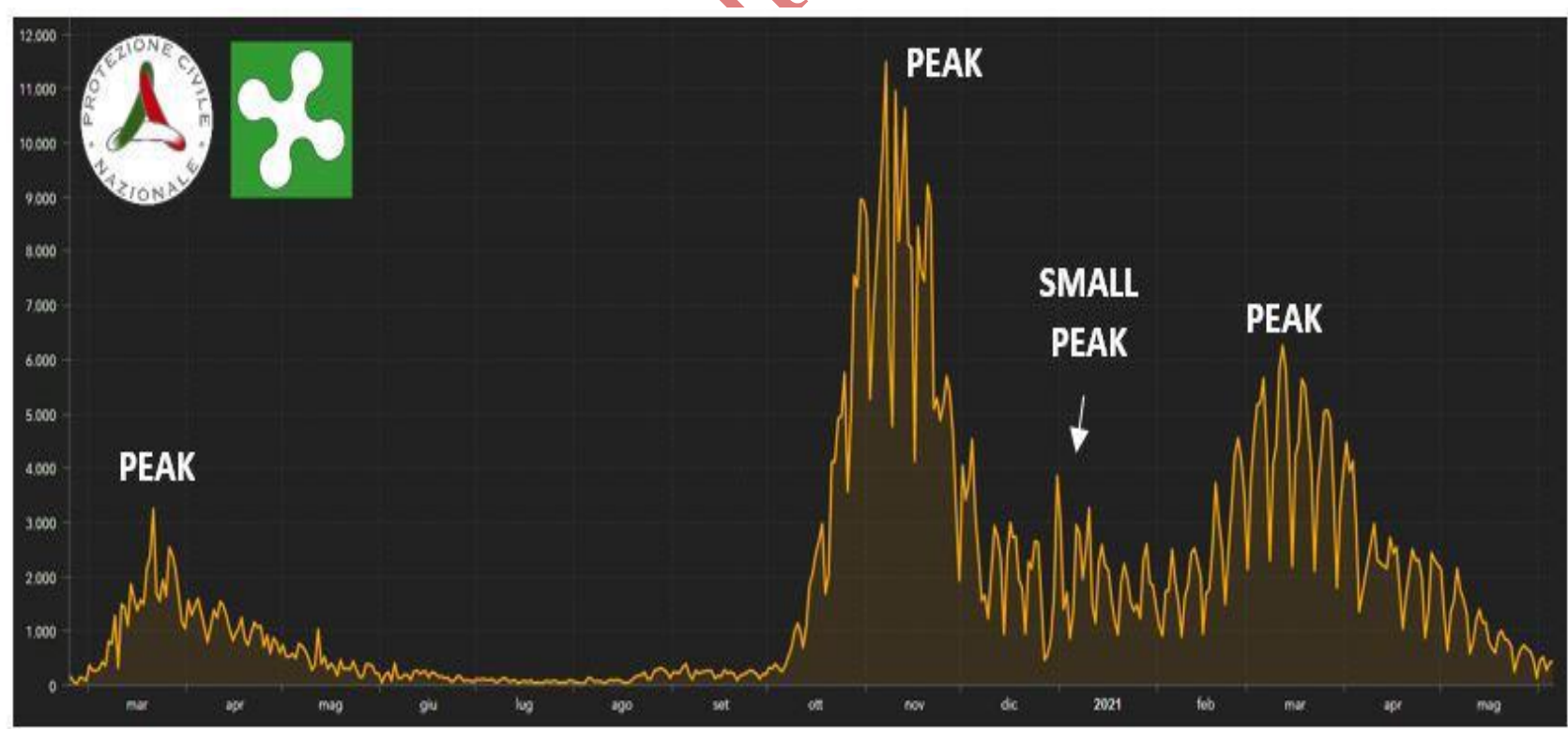

Fig. 10 - Graph showing the evolution of the SARS-CoV-2 infection, from 24 February 2020 to 5 June 2021. Regional trend (Lombardy). On the axis of the ordered, the number of infected are visible, while the temporal context in months is visible on the abscissa axis. Credits: Department of Civil Protection - Presidency of the Council of Ministers. 
Figure 11 - Performance of the Marche Region - 2020-2021

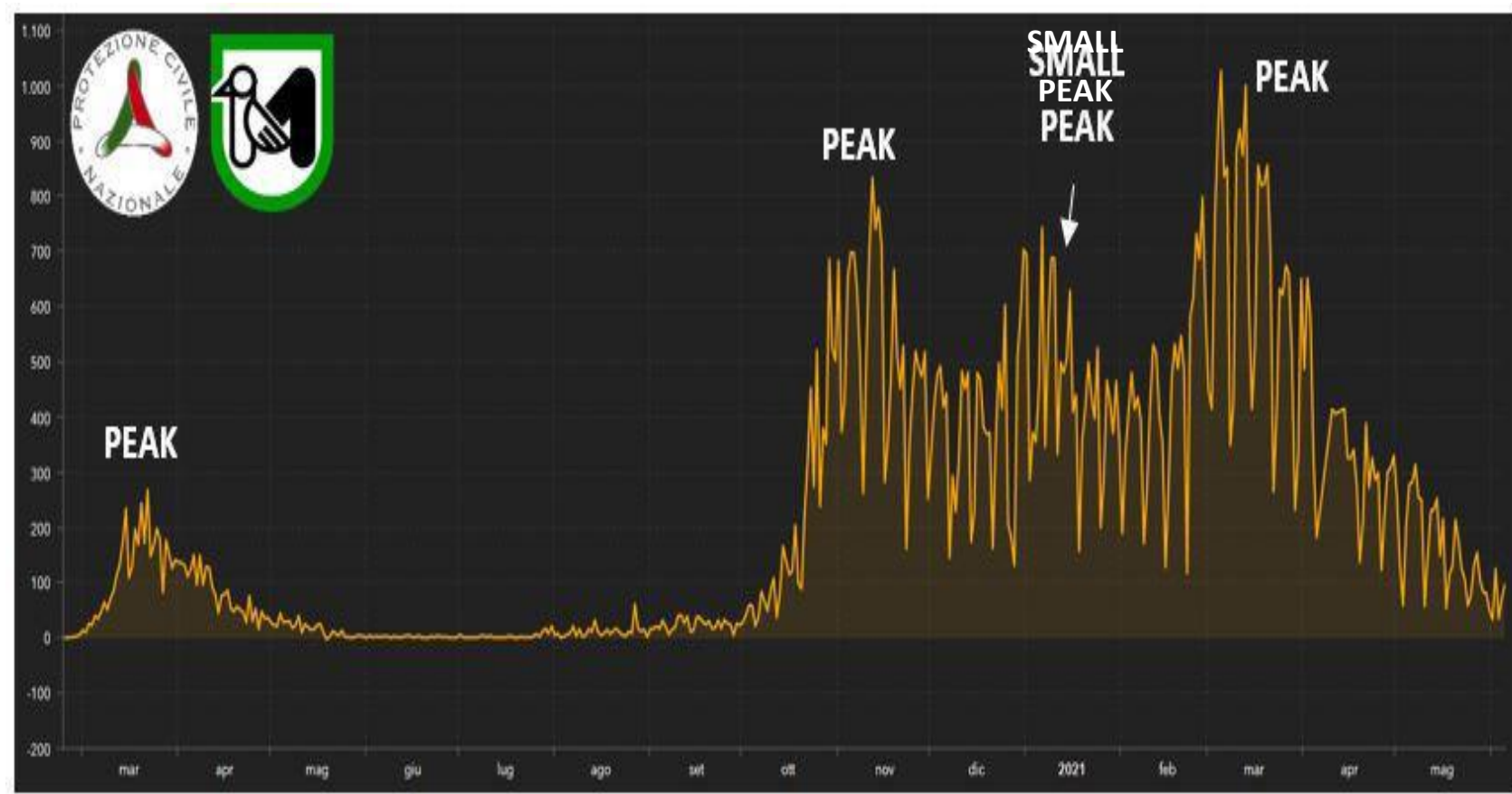

Fig. 11 - Graph showing the evolution of the infection of the SARS-CoV-2, from 24 February 2020 to 5 June 2021. Regional trend (Marche). On the axis of the ordered, the number of infected are visible, while the temporal context in months is visible on the abscissa axis. Credits: Department of Civil Protection - Presidency of the Council of Ministers.

Figure 12 - Performance of the Molise Region - 2020-2021

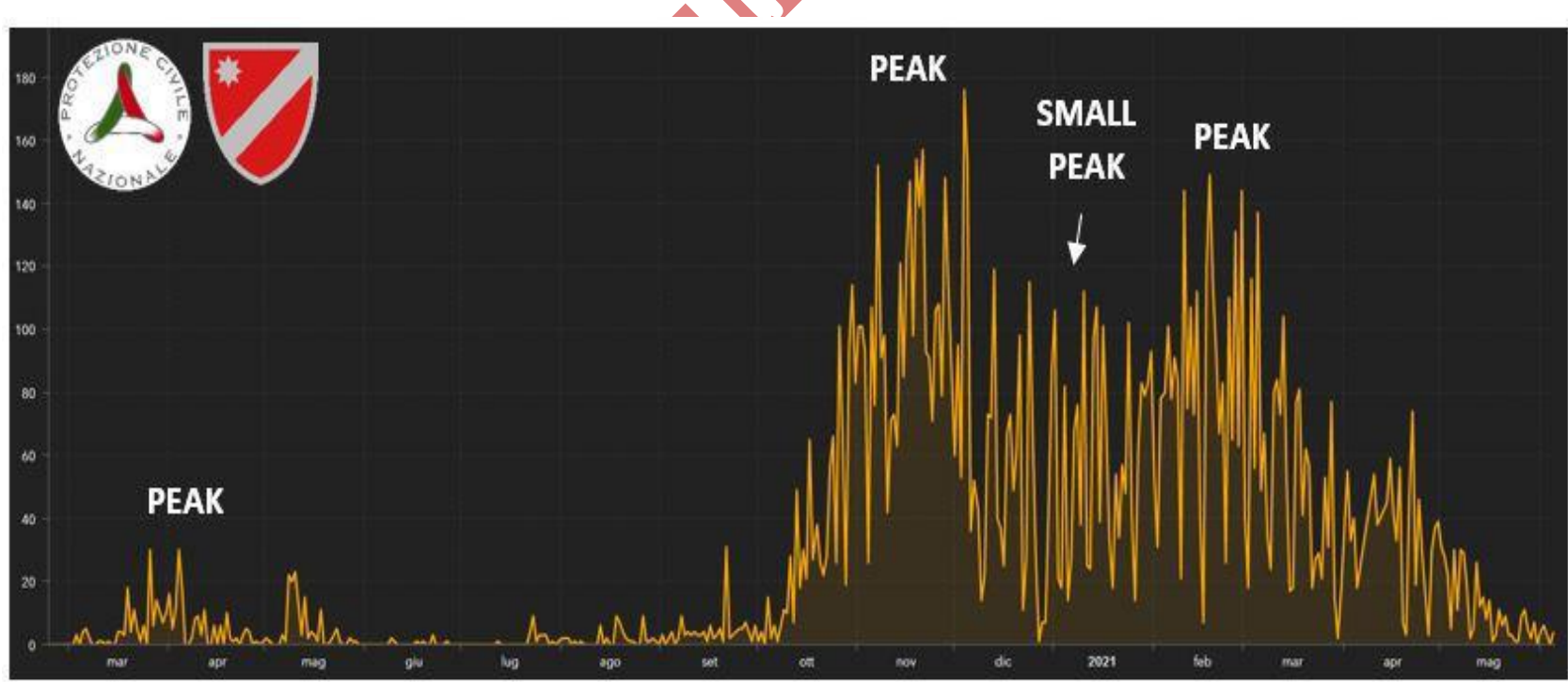

Fig. 12 - Graph showing the evolution of the infection of the SARS-CoV-2, from 24 February 2020 to 5 June 2021. Regional trend (Molise). On the axis of the ordered, the number of infected are visible, while the temporal context in months is visible on the abscissa axis. Credits: Department of Civil Protection - Presidency of the Council of Ministers. 


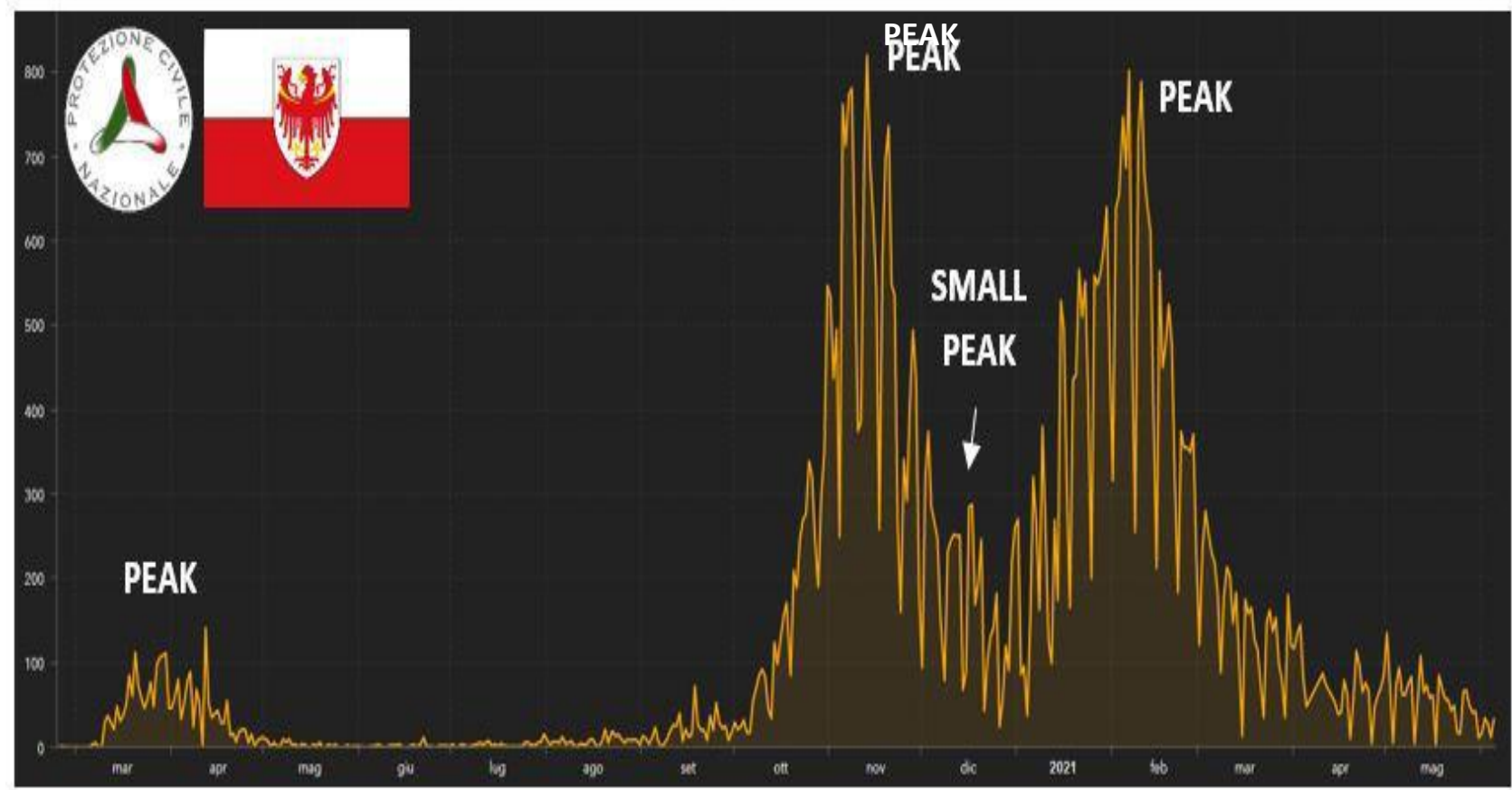

Fig. 13 - Graph showing the evolution of the SARS-CoV-2 infection, from 24 February 2020 to 5 June 2021. Regional trend (P.a. Bolzano). On the axis of the ordered, the number of infected are visible, while the temporal context in months is visible on the abscissa axis. Credits: Department of Civil Protection - Presidency of the Council of Ministers.

Figure 14 - Trend of the Autonomous Province of Trento - 2020-2021

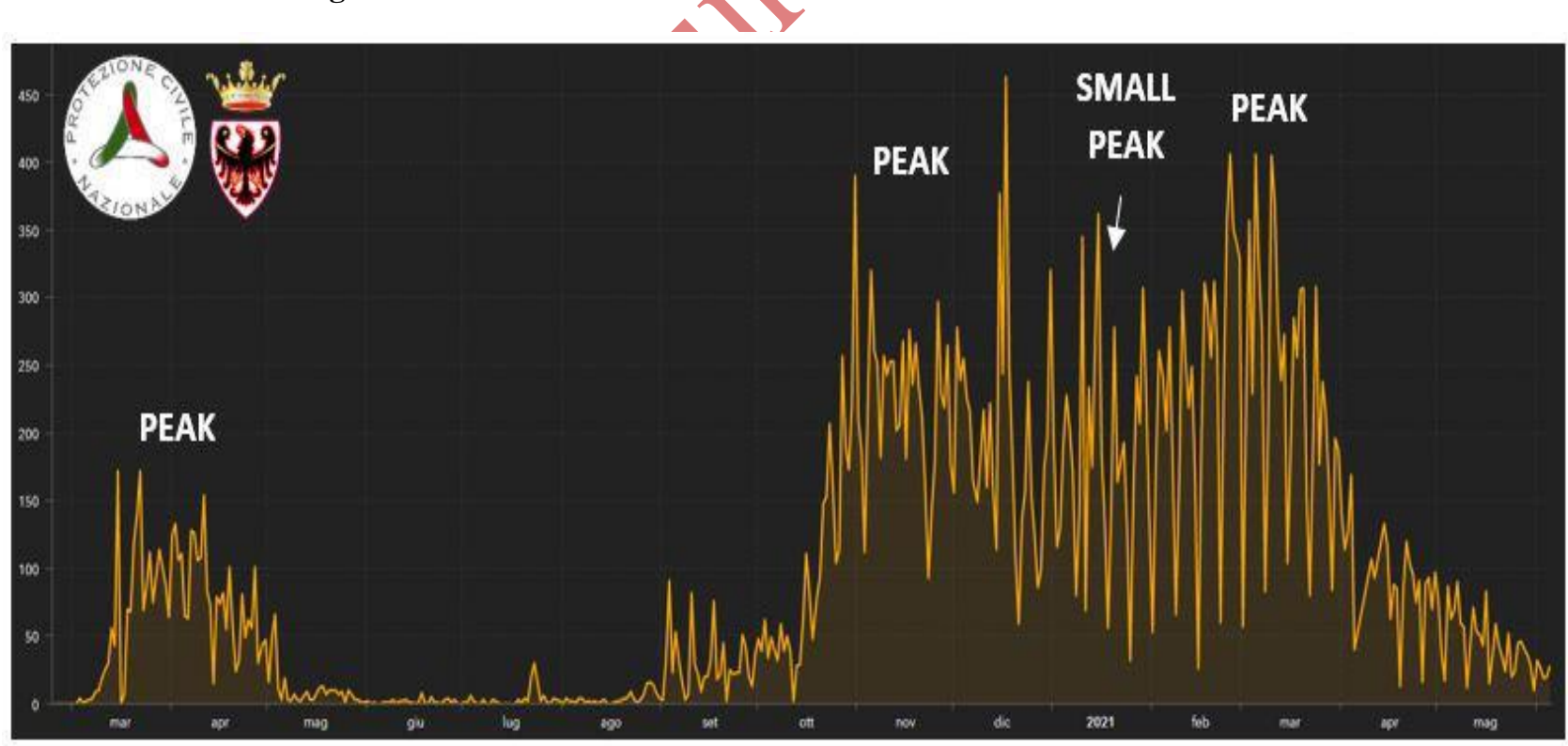

Fig. 14 - Graph showing the evolution of SARS-CoV-2 infection, from 24 February 2020 to 5 June 2021. Regional trend (P.a. Trento). On the axis of the ordered, the number of infected are visible, while the temporal context in months is visible on the abscissa axis. Credits: Department of Civil Protection - Presidency of the Council of Ministers. 
Figure 15 - Trend in the Piedmont Region - 2020-2021

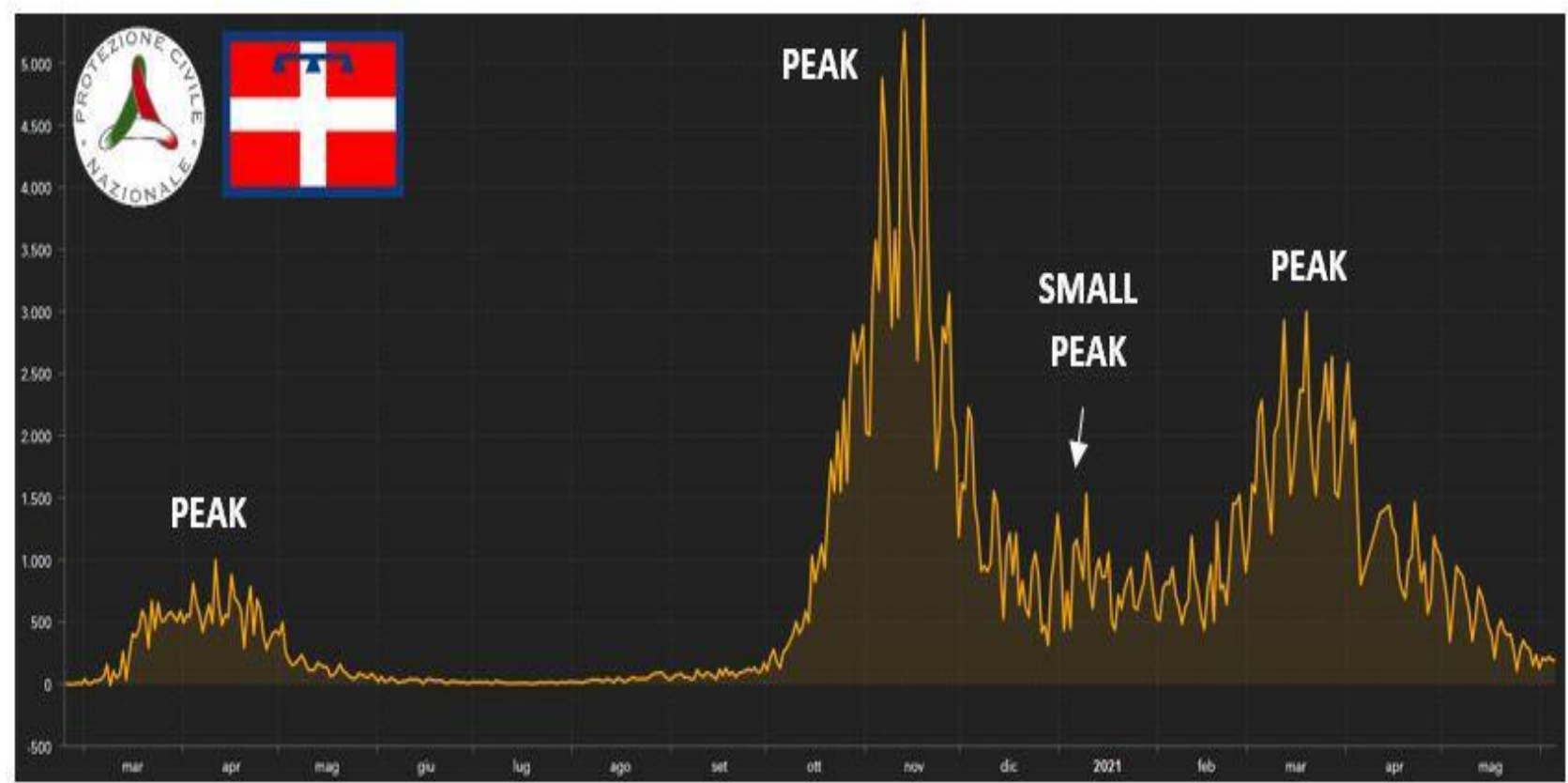

Fig. 15 - Graph showing the evolution of the SARS-CoV-2 infection, from 24 February 2020 to 5 June 2021. Regional trend (Piedmont). On the axis of the ordered, the number of infected are visible, while the temporal context in months is visible on the abscissa axis. Credits: Department of Civil Protection - Presidency of the Council of Ministers.

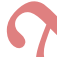

Figure 16 - Trend in the Puglia Region - 2020-2021

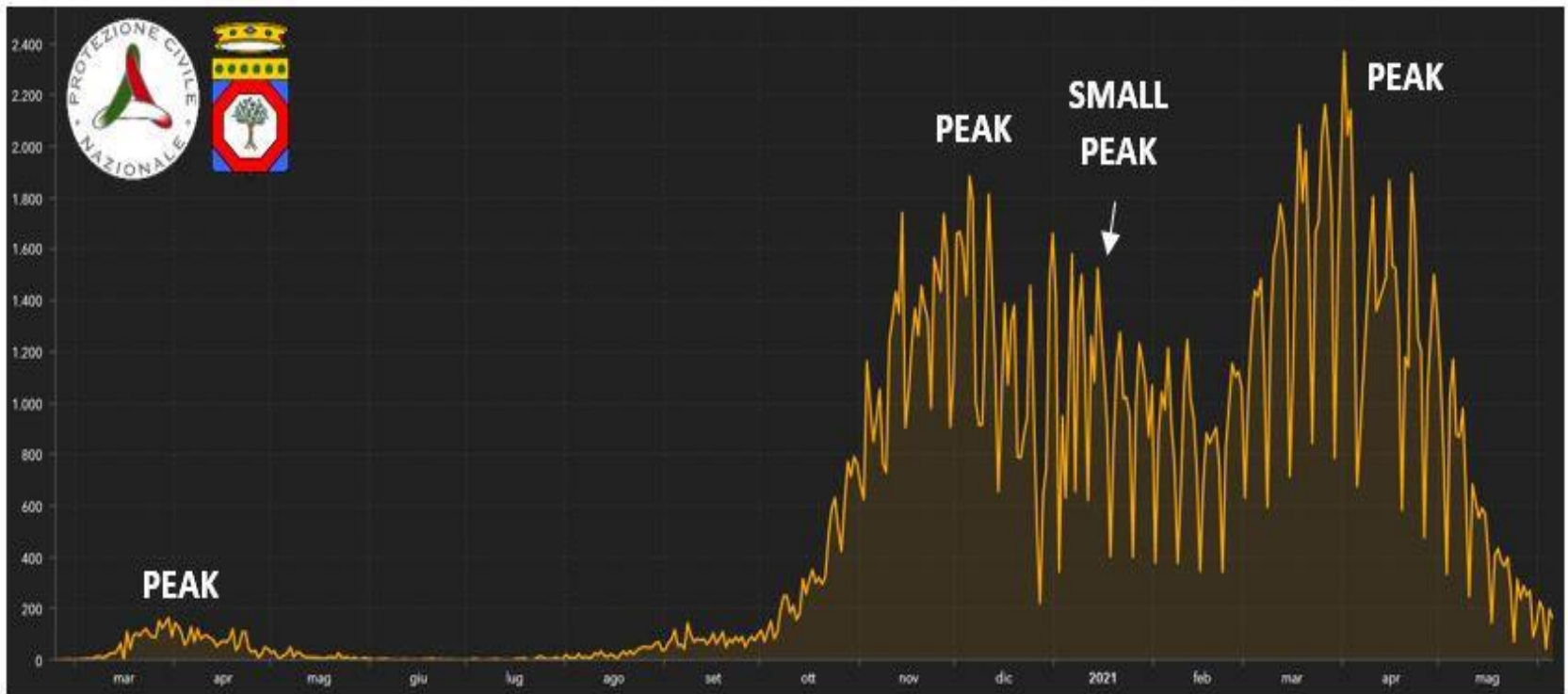

Fig. 16 - Graph showing the evolution of the infection of the SARS-CoV-2, from 24 February 2020 to 5 June 2021. Regional trend (Puglia). On the axis of the ordered, the number of infected are visible, while the temporal context in months is visible on the abscissa axis. Credits: Department of Civil Protection - Presidency of the Council of Ministers. 
Figure 17 - Trend in the Sardinia Region - 2020-2021

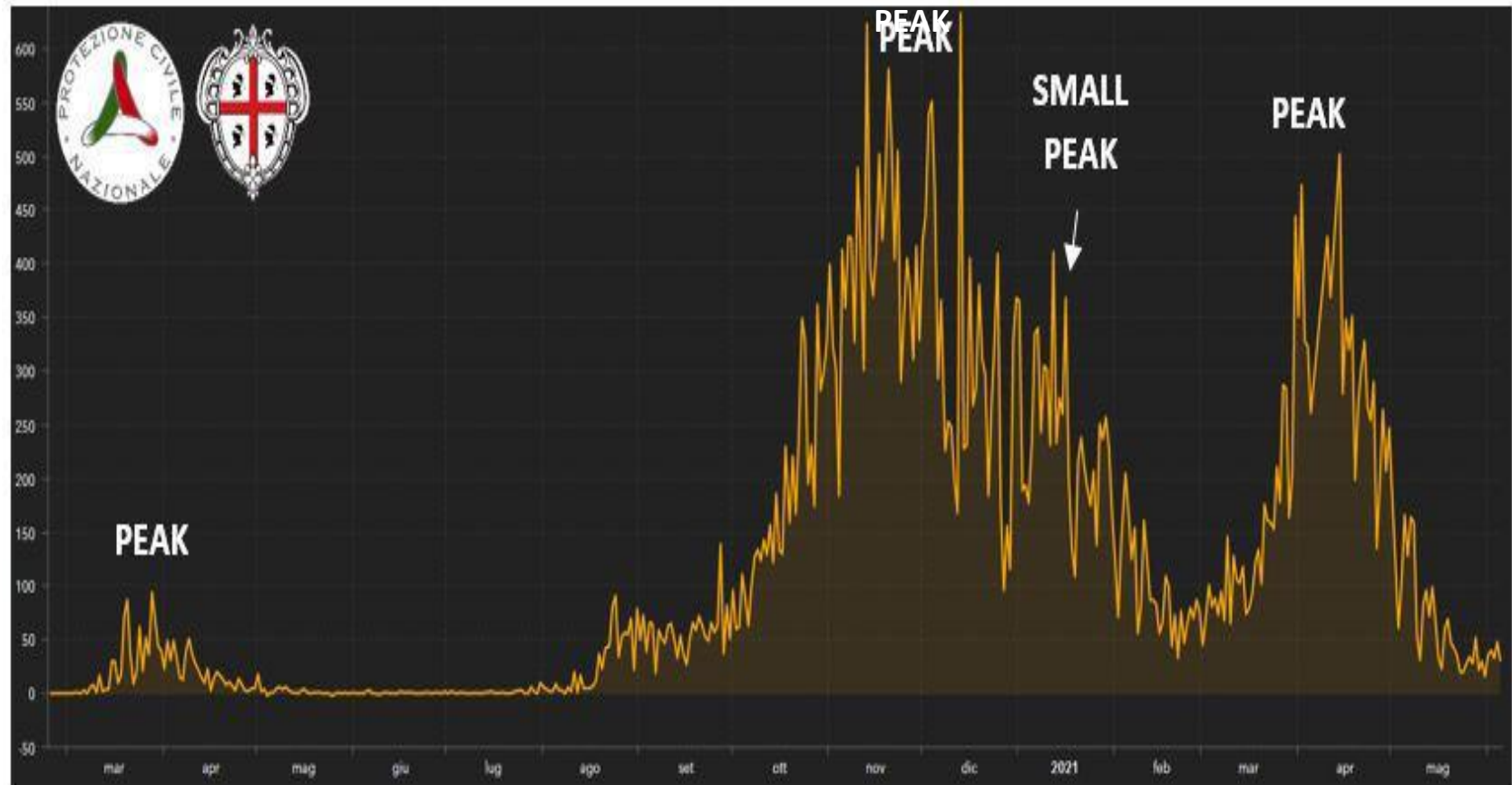

Fig. 17 - Graph showing the evolution of SARS-CoV-2 infection, from 24 February 2020 to 5 June 2021. Regional trend (Sardinia). On the axis of the ordered, the number of infected are visible, while the temporal context in months is visible on the abscissa axis. Credits: Department of Civil Protection - Presidency of the Council of Ministers.

Figure 18 - Trend in the Sicily Region - 2020-2021

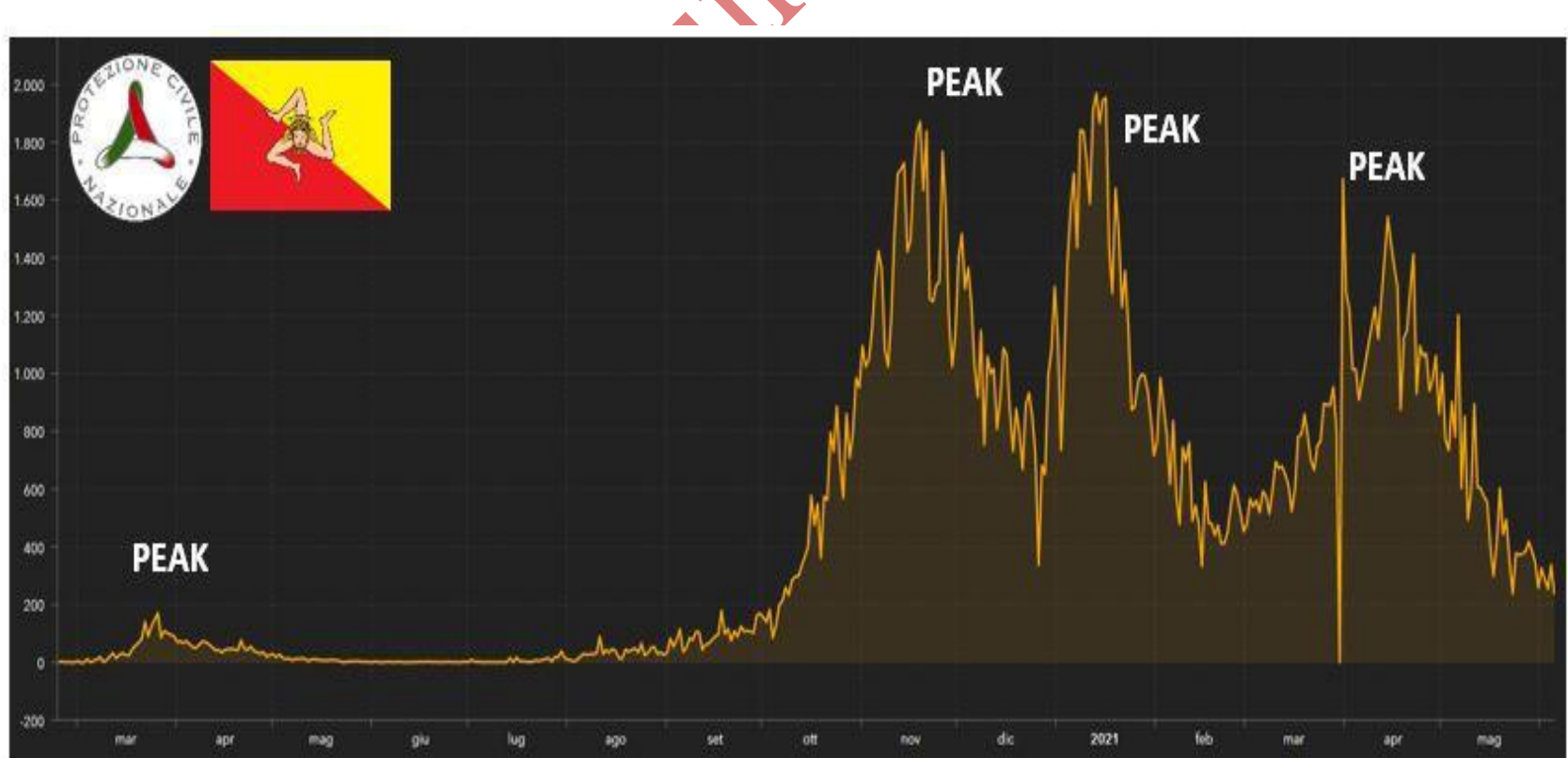

Fig. 18 - Graph showing the evolution of the infection of the SARS-CoV-2, from 24 February 2020 to 5 June 2021. Regional trend (Sicily). On the axis of the ordered, the number of infected are visible, while the temporal context in months is visible on the abscissa axis. Credits: Department of Civil Protection - Presidency of the Council of Ministers. 


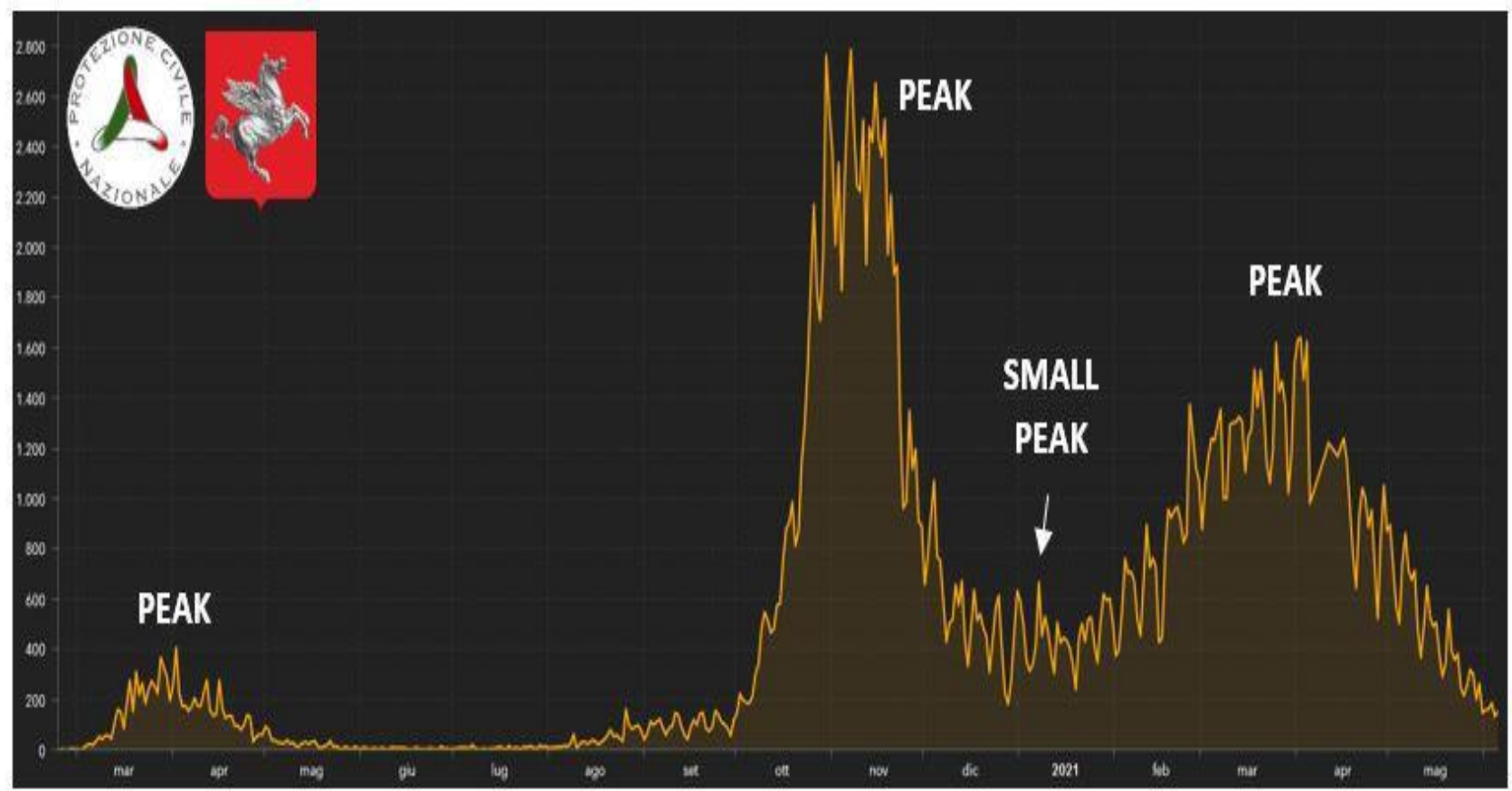

Fig. 19 - Graph showing the evolution of the SARS-CoV-2 infection, from 24 February 2020 to 5 June 2021. Regional trend (Tuscany). On the axis of the ordered, the number of infected are visible, while the temporal context in months is visible on the abscissa axis. Credits: Department of Civil Protection - Presidency of the Council of Ministers.

Figure 20 - Trend of the Umbria Region - 2020-2021
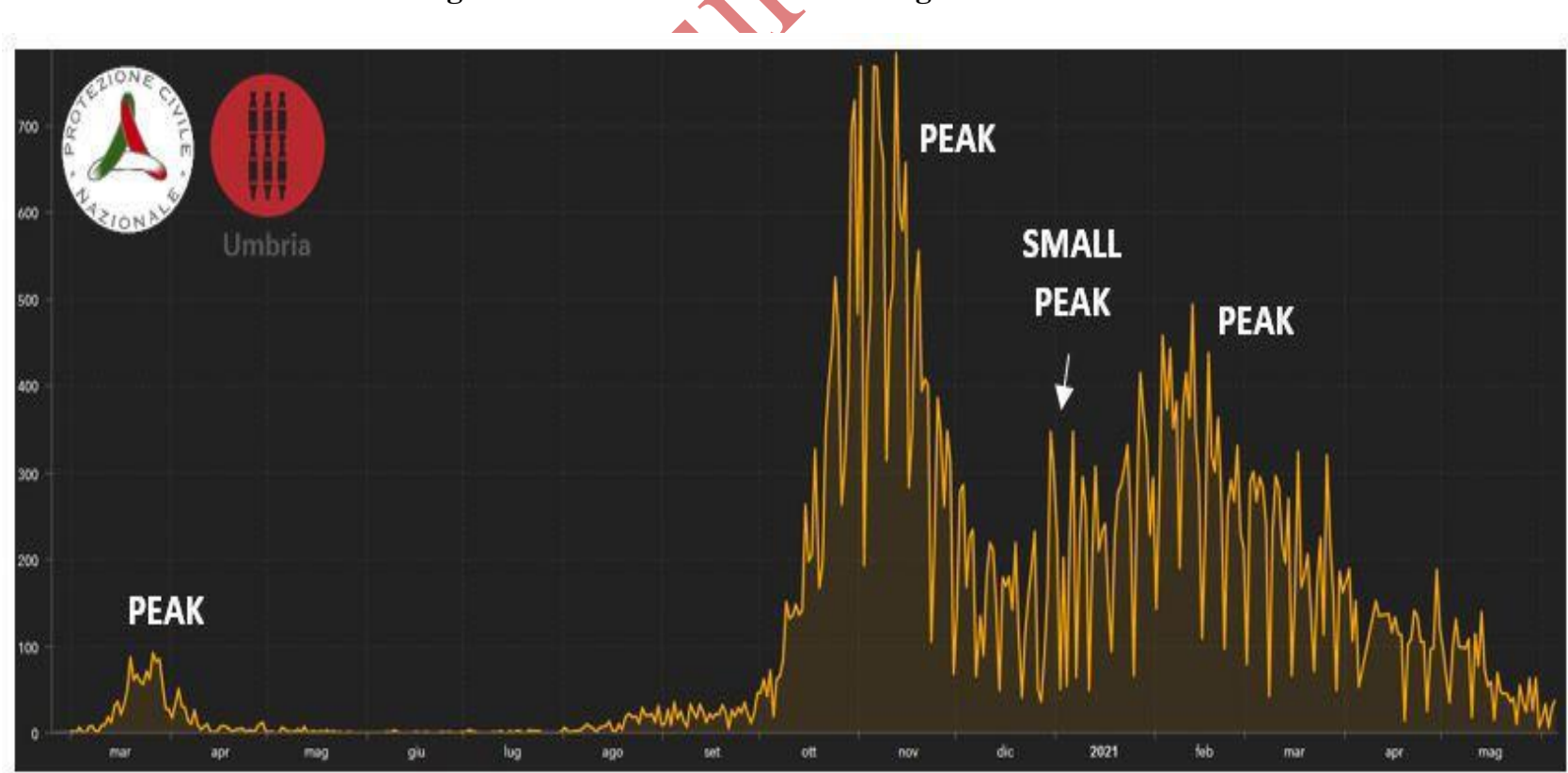

Fig. 20 - Graph showing the evolution of the infection of the SARS-CoV-2, from 24 February 2020 to 5 June 2021. Regional trend (Umbria). On the axis of the ordered, the number of infected are visible, while the temporal context in months is visible on the abscissa axis. Credits: Department of Civil Protection - Presidency of the Council of Ministers. 
Figure 21 - Trend of the Valle d'Aosta Region - 2020-2021

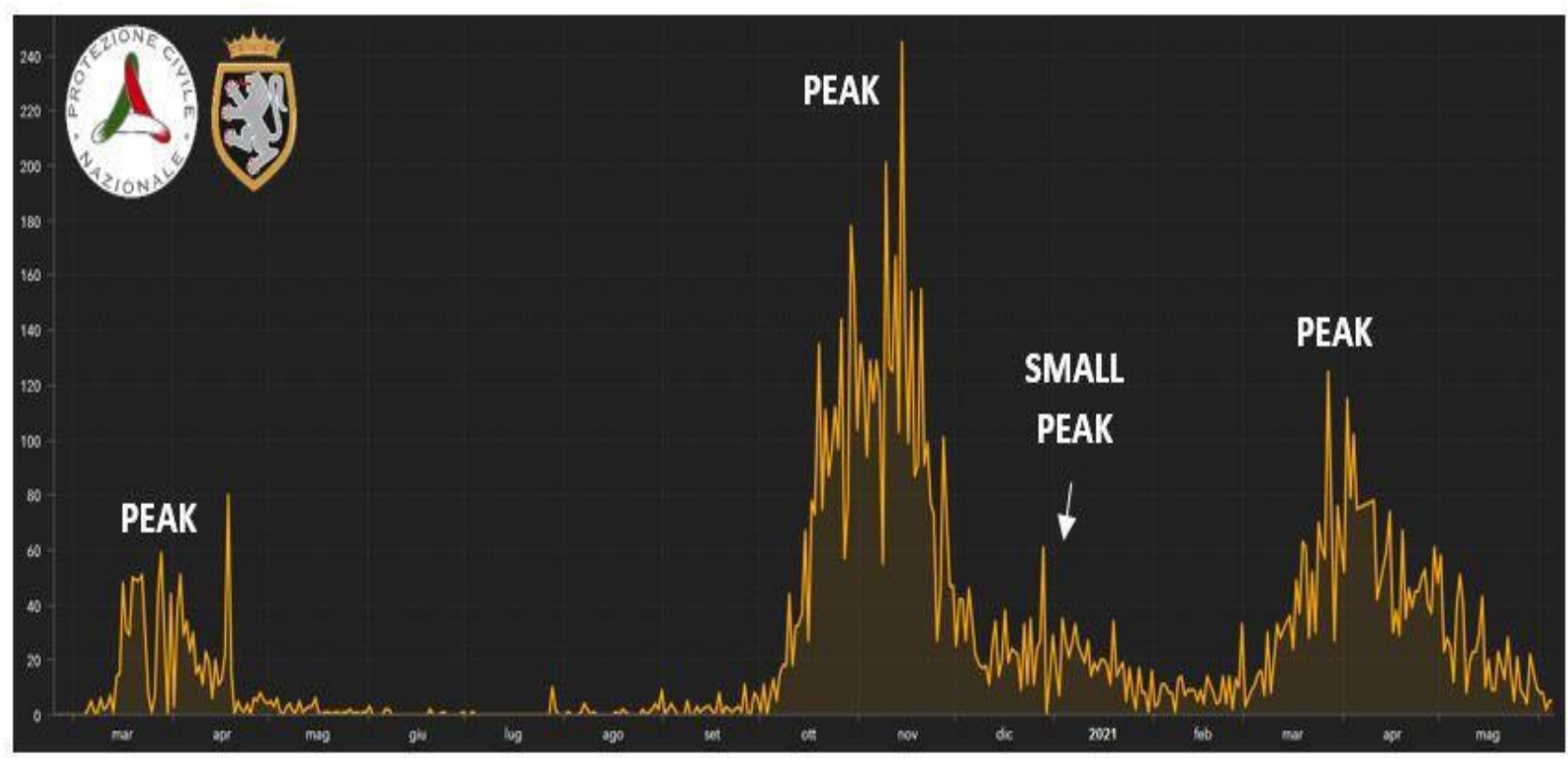

Fig. 21 - Graph showing the evolution of the SARS-CoV-2 infection, from 24 February 2020 to 5 June 2021. Regional trend (Valle d'Aosta). On the axis of the ordered, the number of infected are visible, while the temporal context in months is visible on the abscissa axis. Credits: Department of Civil Protection - Presidency of the Council of Ministers.

Figure 22 - Trend in the Veneto Region - 2020-2021

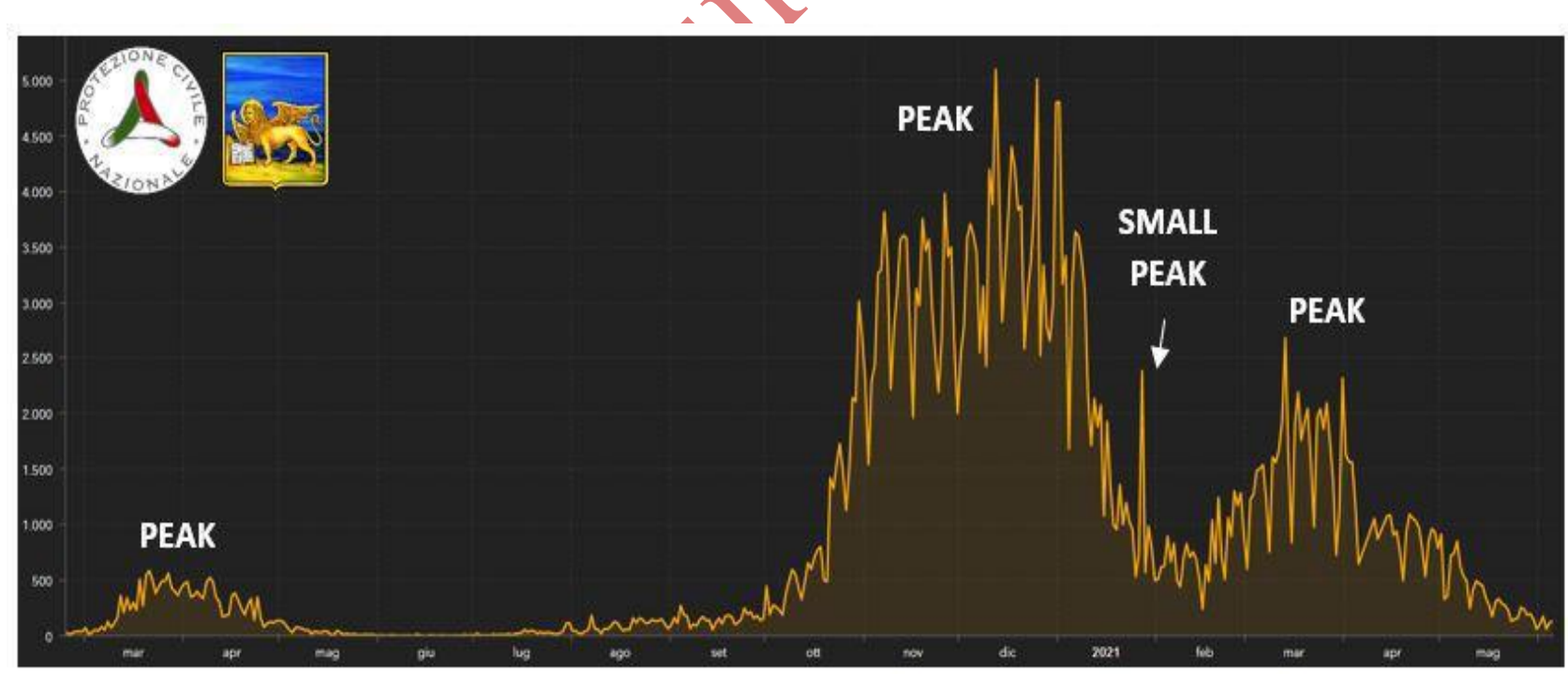

Fig. 22 - Graph showing the evolution of the SARS-CoV-2 infection, from 24 February 2020 to 5 June 2021. Regional trend (Veneto). On the axis of the ordered, the number of infected are visible, while the temporal context in months is visible on the abscissa axis. Credits: Department of Civil Protection - Presidency of the Council of Ministers. 
In the same period considered, the European trend confirmed how the Italian trend are completely superimposable, although with some differences due to local factors that we will soon analyze (Fig. 23).

Figure 23 - European trend - 2020-2021
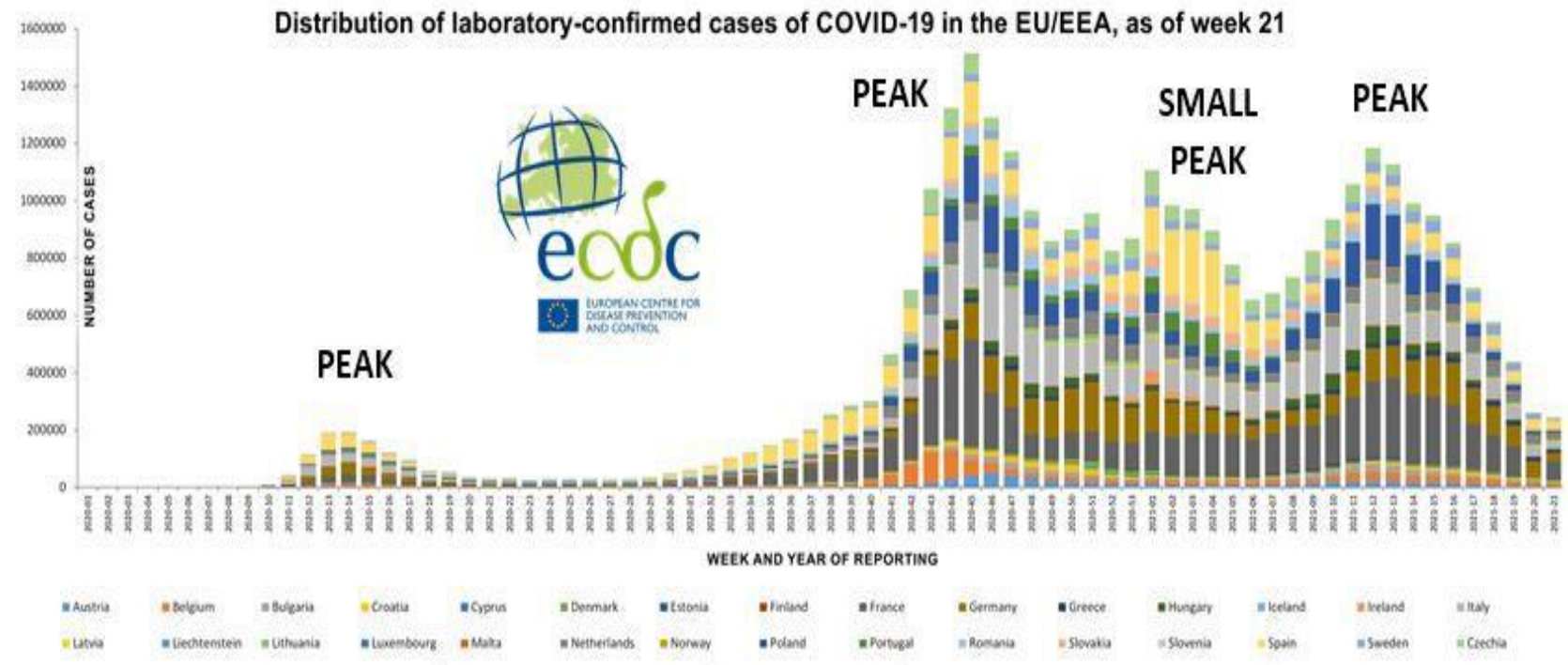

Fig. 23 - Graph showing the progress of the infection from COVID-19, in the European area. On the axis of the ordered, the number of infected are visible, while the temporal context in months is visible on the ASSISSE axis. Credits: European Center for Disease Prevention and Control, An Agency of the European Union.

This means that the basis of the trend of the spread of the new Coronavirus (SARS-COV-2) there must be a factor that identifies its life cycle.

The increase takes place six cold periods of the year [23], while the infection descends and almost totally disappears in the periods of the year that are warmer (beautiful season).

Why does this happen?

\section{3 - Hypothesis}

At this point we go to analyze what the factors that define the vital trend of the new Coronavirus (SARSCOV-2), factors that we can assume may cause its diffusion or vitality.

\section{Climatic / environmental factors:}

$\checkmark$ Environmental temperature.

$\checkmark$ Environmental humidity.

$\checkmark$ Solar radiation (UV rays, IR, X, range).

$\checkmark$ Natural radioactive fund / ionizing particles (muons, particles $\alpha, \beta$ particles, cosmic rays)

$\checkmark$ Meteorology.

$\checkmark \quad$ SpaceWeather linked to solar activity.

\section{Individual factors:}

$\checkmark \quad$ Immune system deficit.

$\checkmark \quad$ Personal behaviors and wrong lifestyle. $\checkmark$ Work.

$\checkmark$ Stress.

$\checkmark \quad$ Presence of other pathologies.

$\checkmark$ Incorrect behavioral standards.

$\checkmark$ Lack or deficit of specific intrinsic factors of the organism.

The factors considered, in this study are not only those of a personal type or concerning our body, or for example the genetic predisposition in mismatch, due to deficit, for example of the immune system, or cause of work, stress and exposure then At the etiological agent, but it goes to consider what others did not consider until now, as the environment in which we live.

It seems obvious, but it is not, yet few researchers consider solar radiation as a real factor able to mitigate viral and bacterial proliferation.

The radiation of the primary natural radioactive fund is capable not only to make ourselves sick, like when we 
breathe the radon $\left(\mathrm{Rn}_{222}\right)$ [17] [18], but it is able, also to influence microorganisms, their growth and dissemination, because able to penetrate their wall and destroy part of their DNA or genetic code.

As is in fact known, ionizing radiation can damage living cells, altering the genetic material (DNA).

These DNA alterations can cause mutations, and such mutations can cause cancer.

If the damage is too severe, for example in the case of high doses, affected cells can also die. A virus is also subject to these destructive effects [15] [16].

Secondary natural radioactivity also determines these issues on microorganisms, their vital cycle and their spread, for example by radiation from particles coming from the sun or space by means of cosmic rays [16] [20]. Sscience already states this [49] [50], and therefore it is possible to hypothesize that even for viruses these effects exist [21].

During the summer period, or that characterized by the period in which the climate is more mild and warm, the data show that Coronavirus tends to disappear, precisely because these factors can affect its life cycle.

We do not only talk about individual factors, such as the lifestyle that in these warmer months, changes radically, pushing people to spend more time away from home and in the sun, but we also talk about the greatest effect due to solar radiation, to the greater

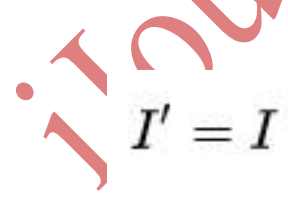

There is a maximum quantity with perpendicular incidence, both the surface affected by the same amount of radiation and the thickness of the atmosphere crossed by these is increased.

This creates the variations of daily, annual and latitudinal radiation.

This would explain precisely because in the warm months, in which the angle of incidence of sunlight increases compared to other periods of the year.

And it is precisely for these rays and for their greater incidence that the incident energy is absorbed by the earth's surface and thus contributes to its heating, in a variable way depending on the latitude and the type of surface [22].

The virus, adherent on our bodies, as well as garments or environments, surfaces, if more than the sun, are amount of cosmic rays able to reach us and reach our natural habitat, because assisted in good weather, in favorable weather conditions that filter these ionizing particles less, and also to the fact that people are subject to greater light irradiation solar and cosmic rays, why not locked up in their homes that shield most of such radiation or electromagnetic emissions capable of damaging the genetic material of the Coronavirus.

This is a considerable hypothesis due to the characteristics of the phenomena considered, even if studies already demonstrate this. Even ultraviolet rays (UV-C lamps - black light) can interfere with the life of this virus family, and therefore it is normal for the vital cycle of such microorganisms ceases almost totally in the summer period, to start growing again in the autumn period, winter and in general in the cold months [23], where solar radiation is less, even due to the variation of the incidence of sunlight which are less perpendicular to the earth's surface, and where the viruses can replicate again in individuals who are indoors and with climates more respectful for life and Virus replication.

In this case to understand this hypothesis, we can talk about "incident radiation", which is that solar radiation that sells all or part of its energy on any object or body that meets on its way.

According to the law of Lambert the amount of radiation that affects the surface unit is proportional to the incidence corner of the angle: susceptible to its effect [49]; even the natural environment (habitat) is more subject to such radiation or electromagnetic emissions, considerably contrasting on the virus virus cycle [50].

The characteristics on the virus vital cycle, observed in the graphs examined in this study, can therefore depend on the effect of the action of solar radiation as well as from the variation of our lifestyle?Hypothetically it seems that there may be a close relationship with this hypothesis.

If we analyze the vital trend in the infection from COVID-19, it is possible to observe as even in the absence of specific drugs and various pharmacological prophylaxis, the virus seems to start disappearing in the same temporal context, or between half and the end of March, to start recurring between the end of September and the beginning of October, overriding 
throughout the cold period, they are to disappear around half / late March, or when the climate begins to become warmer, due to the solar radiation [51].

There is no doubt about this evidence.

Some important and non-recently considered considerations can be observed by going to see the same national trend of SARS-COV-2 infections, in consideration of the same time period, without (2020) and with vaccinations carried out on the population (2021)

This is visible within the Fig. 24 and of Fig. 25 (Graphics), always drawn up from the official source, or from the Italian Civil Protection Department, and official source of the Italian Ministry of Health.

Figure 24 - Italian Trend: from 2 March 2021 to 5 June 2021

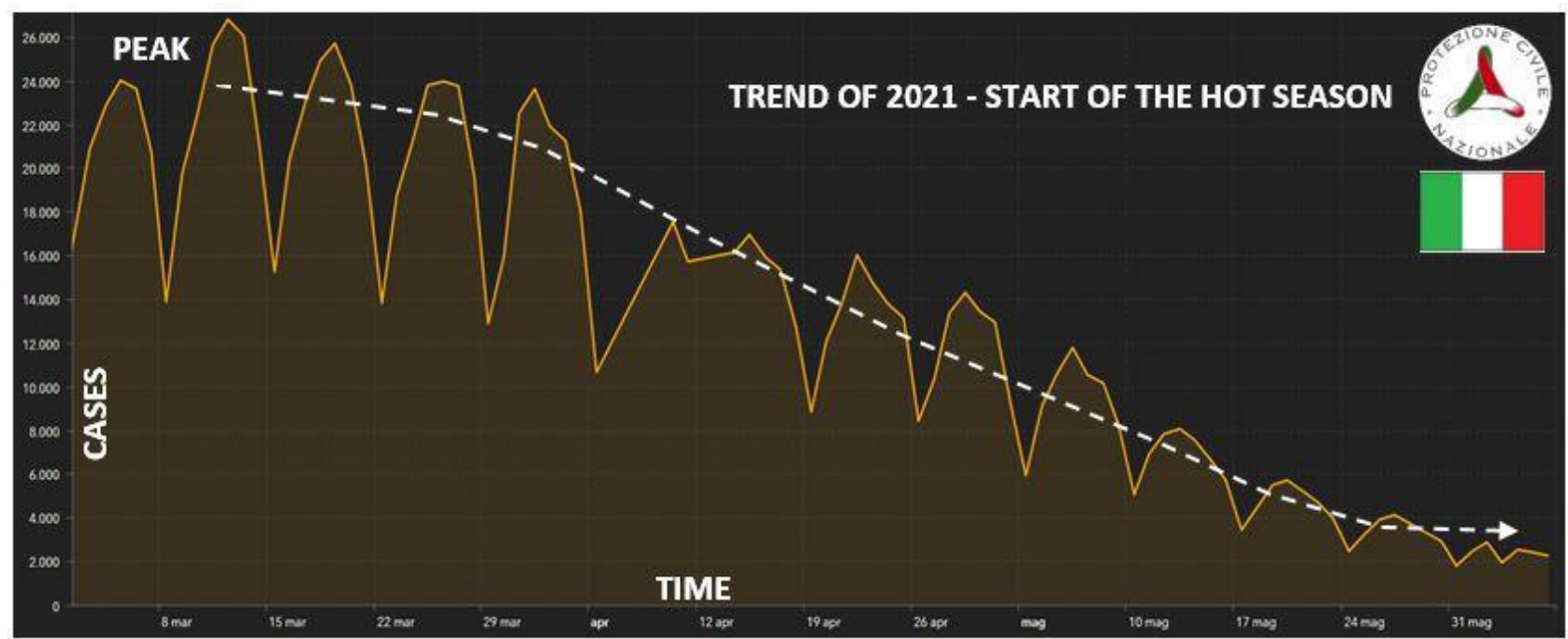

Fig. 22 - Chart showing the evolution of the infection of the SARS-CoV-2, from 2 March 2021 to 5 June 2021. National trend following vaccinations. On the axis of the ordered, the number of infected are visible, while the temporal context in months is visible on the abscissa axis. Credits: Department of Civil Protection - Presidency of the Council of Ministers.

The fig. 24, it shows how to start from the second week of March 2021 (new coronavirus infection peak), the infection is quickly descent, are to achieve great minimal (up to 5 June 2021). The same variation can we observe it in 2020, considering the same time period (Fig. 25):

Figure 25 - Italian trend: from 2 March 2020 to 5 June 2020

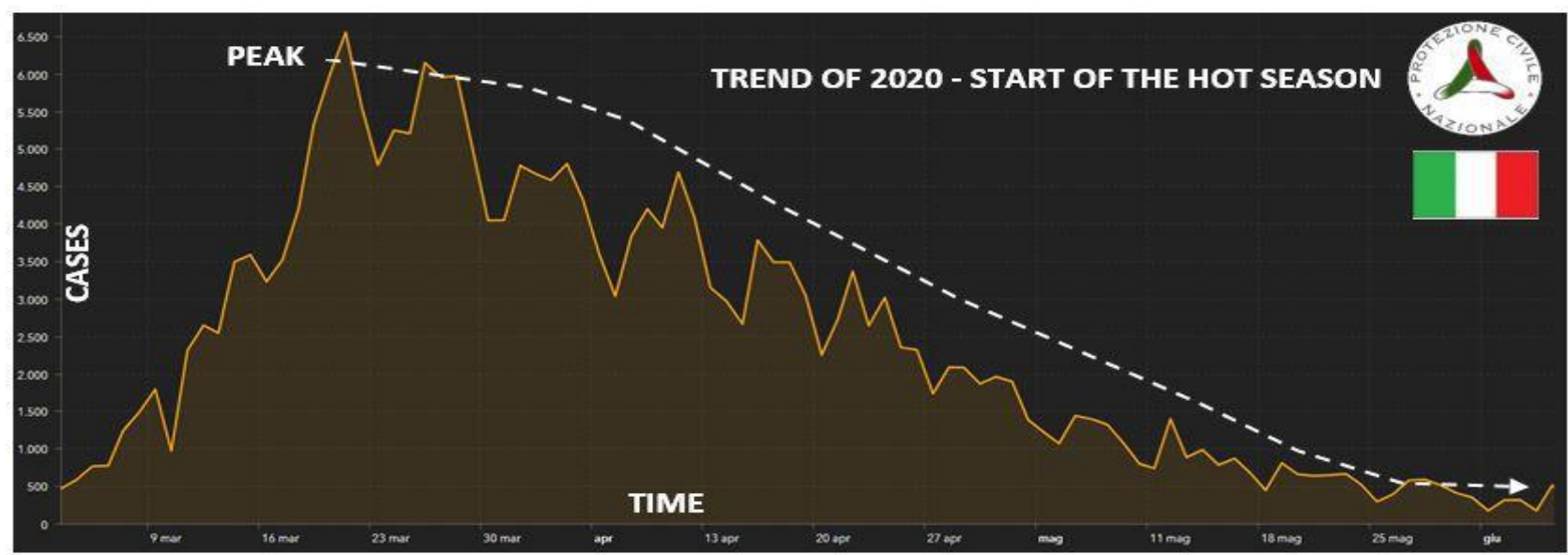

Fig. 25 - Chart showing the evolution of the infection of the SARS-CoV-2, from 2 March 2020 to 5 June 2020. National trend without the use of vaccines. On the axis of the ordered, the number of infected are visible, while the temporal context in months is visible on the abscissa axis. Credits: Department of Civil Protection Presidency of the Council of Ministers. 
The evidence demonstrates (albeit initially during the first two weeks of March 2020, the data was not sufficient to detect the real number of infected people due to the few pads / screening carried out, compared to the following year), which the peak of New Coronavirus infection, which took place in mid-March 2020, was then quickly to reduce during the following weeks, without the use in this case of pharmacological prophylaxis (Fig. 25), Just as the following year (March / June 2021), when there was already a certain percentage of patients subjected to pharmacological prophylaxis against the COVID-19 (Fig. 25).

This would be to demonstrate how on the general trend of the European pandemic curve it would not affect the action of the use of drugs, because it would be the normal virus vital cycle. On this feedback it is possible to consider the various specific graphs for each Italian region (Fig. 2, 3, 4, 5, 6, 7, 8, 9, 10, 11, 12, 13, 14, 15, 16, 17, 18, 19, 20, 21, 22), compared to the national trend (Fig. 1) and the european one (Fig. 23).

In fact, the reason for which, finding us in different places, the world chart, the European, the National
Italian and Regional Chart, are substantially identical (Fig. 26).

If these are different areas, both from a climatic and geographical point of view, the curve of infections should be different, instead the progress of the infection is the same, albeit with their mutual differences.

This could confirm how to actually the virus and its propagation follow modes other than those hypothesized until today, or in any case that the influence of certain customs or methodologies developed to stop the contagination curve, actually interfering at least on the virus life cycle, which still seems to always decrease in the hot months, even if the lock-down is removed, and seems to start again to grow and replicate themselves in the cold months [23], when the lock-down is active, but the virus "reappears" with all the His strength because of the coldest climate.

Same data are extrapolable from the global data of infections, as visible in the Fig. 26.

Figure 26 - World Trend: from 2 March 2020 to 3 June 2021

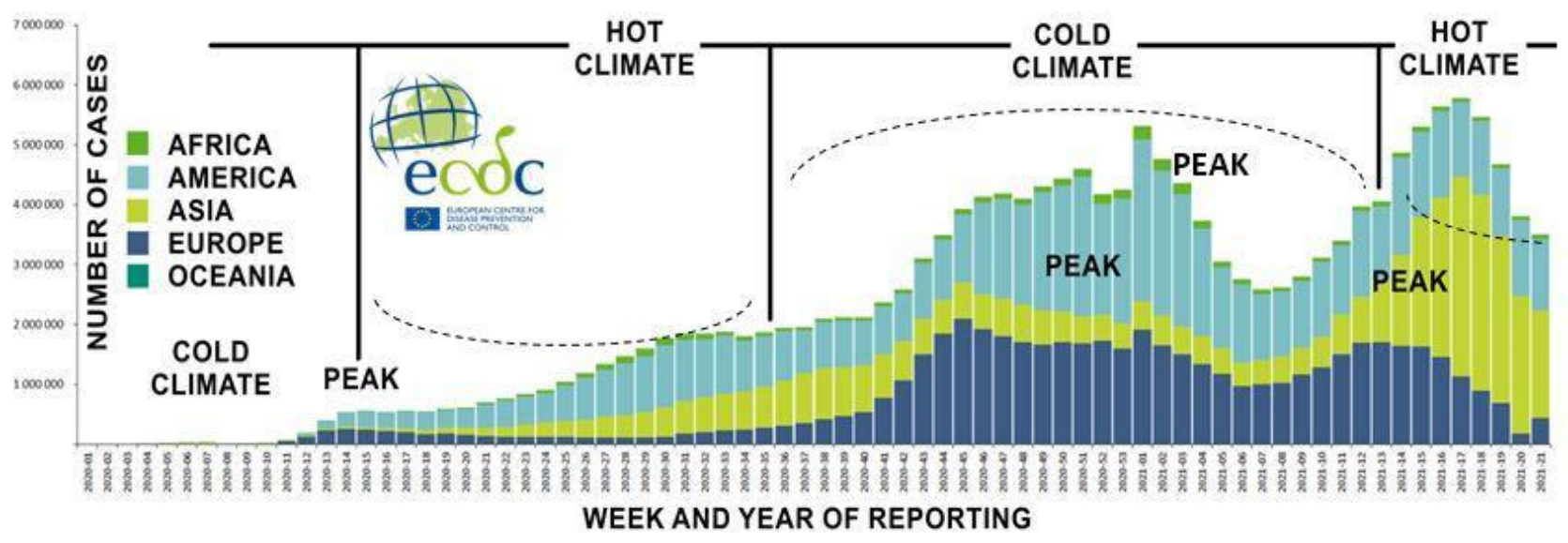

Fig. 26 - Chart showing the trend of the infection from SARS-CoV-2, in the world area. On the axis of the ordered, the number of infected are visible, while the temporal context in months is visible on the ASSISSE axis. Credits: European Center for Disease Prevention and Control, An Agency of the European Union.

The graph visible ina Fig. 26, shows clearly how the new Coronavirus can be replicated more in the period in which the climate is cold, and drastically decreases this feature when the climate starts to become warm.

\section{0 - DISCUSSION}

The hypothesis that the new Coronavirus, responsible for the COVID-19, can be susceptible to greater solar radiation (hot seasons) [48] [49] [50], and sensitive
This indicates as also globally and not only at national level (Italy), the new Coronavirus leads to the same way. This life cycle is obvious.

then to certain electromagnetic emissions (UV-C rays) or to Natural radioactive particles (whose nature is spatial) could allow new nursing strategies or 
innovative use of simple prophylaxis so that this infection can be better mitigated.

There are already evidence that highlighted as the vital cycle of viruses and pandemics, in history, is linked to solar activity [52], not at home the graph shows this.

For example, use of UV-C lamps, present in hospital environments, or in the environment of hospitalization of the patients (programmed ignition), could allow to effectively reduce the transfer of the virus from the environment to people; Not only could it allow a lot of the virus infecting a lot, if this dispersed in the environment [24] [25] [26] [27] [28] [29] [30] [31] [32] [33] [34] [35] [36] [37] [38] [39] [40] [41] [42] [43] [44] [45] [46] [47].

We could mitigate better strategic choices including that the viral activity of the new Coronavirus is mainly determined by natural factors, linked to solar radiation (which possesses in themselves many types of electromagnetic emissions including UV-A - UV-B and part of UV -C species if artificially generated (Fig. 27) and the most mild climate, compared to the colder and humid periods of the year [23] which are able instead of prolonging the life of the viruses. On these important information it would be possible to medrically use therapies and prophylaxis on patients at risk, instead of proceeding for example in the use of mass prophylaxis, also distributed in periods in which the virus is not active.

A huge speech could be considered on the ergonomics of household or welfare environments (even hospitals), where sunlight could be used as a direct energy "weapon, to decrease the possibility of diffusion of coronavirus in closed rooms (but generally influence On the dissemination of all types of viruses and bacteria). This would also mean saving non-recently monetary resources, as well as a better management of health personnel in this area (different vaccine phases, aimed at certain periods of the year, and the use of IPD - Individual Protection Devices when there would be really need).

Figure 26b - Trend of the dead for COVID-19 - March-June 2020-2021

\section{New deceased for Covid-19 - Difference of mortality recorded in the two periods considered (from 24 February 2020/2021 to 5 June 2020/2021)}

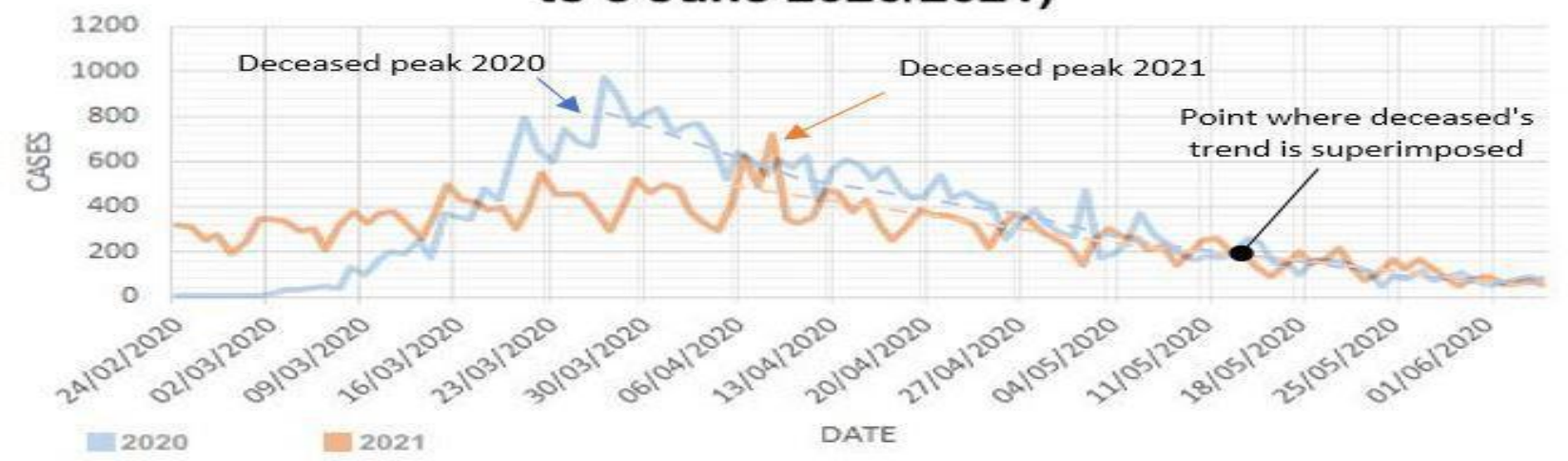

Fig. 26b - New deceased for COVID-19 - Difference of mortality recorded in the two periods considered (from 24 February 2020/2021 to 5 June 2020/2021) - Credits: Department of Italian Civil Protection.

The Fig. 26b, provides important indications on the evolution of the dead in Italy due to the COVID-19 in the period between 24 February 2020 and 5 June 2020, and on February 24, 2021 and 5 June 2021.

Note as in 2020, there was The famous mortality peak due to the lack of knowledge referring to the complications that the COVID-19 determined in patients (mainly for pulmonary embolism), after that the trend of mortality began to descend in March 2020. In this period there was not there It was no vaccinal prophylaxis since this had begun in December 2020.

Therapies had already been experienced in other areas of care, this time used against SARS-COV-2 (between these antivirals and antiroumatoids).

In the same temporal context, but translated by 12 months, the peak of the mortality of 2021 is visible and the sudden decline in mortality that tends to appear identical to that of 2020 .

He deduces himself as the peak of mortality of 2020, although counting a number More than deaths, these were then decreased considerably and much faster than in 2021, the year in which, the number of deaths was lower, but the decrease was descended more slowly. 
In the second half of May 2020 and 2021, the number of deaths seems to overlap as a media, then confirmed the same weekly trend (although with minimal variations observable in both periods), until the end of the time period considered in this study.

This shows how the trend of the two mortality follows the same behavior, or due to different factors from the use of medical therapies or prophylaxis, almost certainly to natural viral activity, to its seasonality.

If this is not the case, it is not explained why in 2020, even with a greater number of deaths, the trend of mortality has seen a quick decrease in the dead, which should have reached the same Valoro observed in 2021 on a temporal difference of at least three weeks of delay.

This means that in 2020, the same number of deaths were reached in 2021 in the second week of May, at the first week of June, precisely for the greatest number of deaths that would have forced the curve to decrease over time.But in reality it did not go at all in this way, as the number of the dead of the respective periods (2020 and 2021), stood at the same observable average in the second week of May (2020 and 2021). How to explain this?

The number of deaths of 2021 , lower than the number of deaths of 2020 must also be explained in statistical terms.

Despite the use of specific therapy and prophylaxis, we would have expected an imposing decrease in mortality, determined by the decrease in infections and

Figure 26c - Trend of the dead for COVID-19 - March-June 2020-2021 conclamated cases of COVID-19, but in reality it was not so.

These questions are licked in a scientific context, the data in fact pose the questions such as not to allow to understand why mortality curves possess a similar behavior (trend), despite having used pharmacological therapies partly very different.

It is certain that from the end of March of both the years (2020 and 2021) mortality has begun to decrease, albeit with small and short differences.

The peak of the mortality of 2021 took place around April 2021, is a poorly explained figure in health terms, given that at that time a certain population had already contracted the virus, had therefore developed antibodies, and a part of the population had vaccinated. How to explain this?

Beyond the hypotheses that it is possible to provide, the graph of the Fig. 26b, it indicates how the absolute behavior of mortality in Italy follows a specific trend that seems to follow the seasonality and the terrestrial climate.

If we go to analyze how this number of deaths have gone to distribute in the period we considered from (24 February 2020 to 5 June 2020 and from 24 February 2021 to 5 June 2021), we can see how the number of deaths of the period 2020, the peak with the largest number of absolute deaths have been in March (Fig. 26c), while for 2021, the peak has moved to April (Fig. 26d).

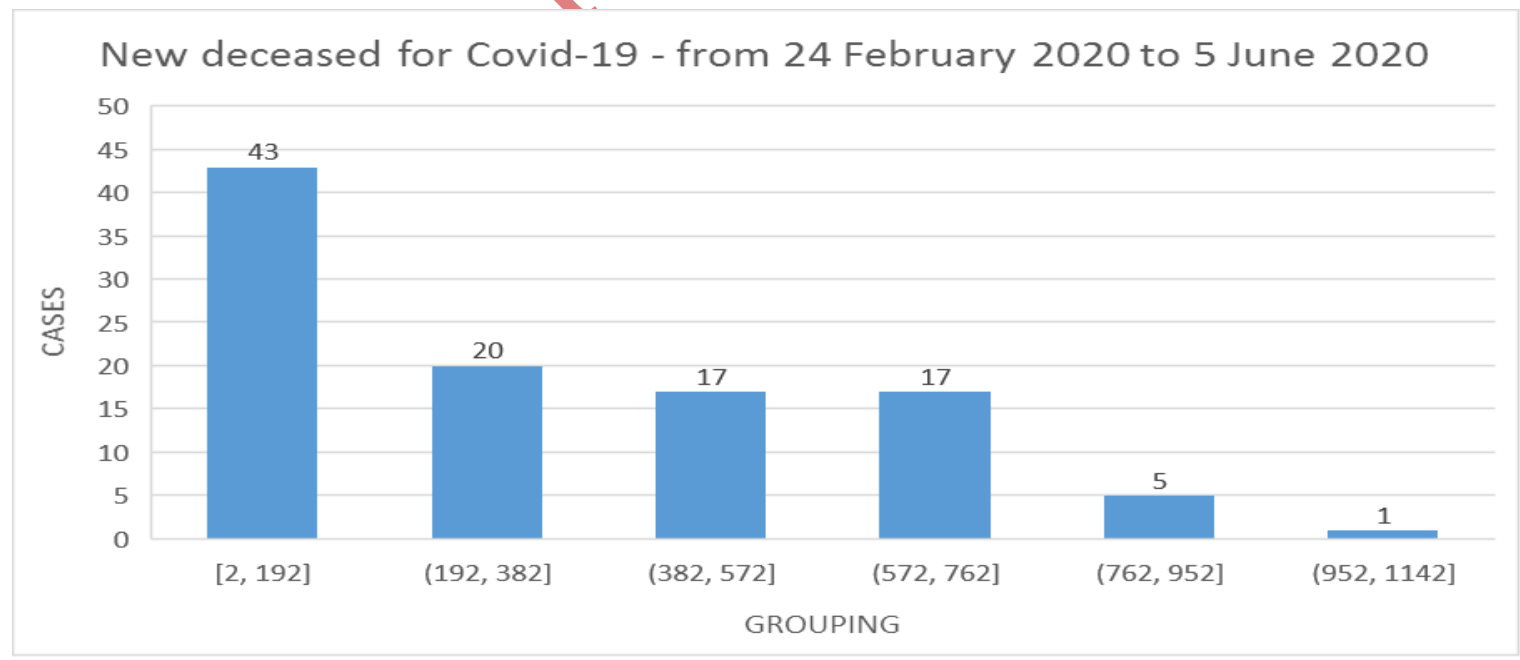

Fig. 26c - Grouping of the New deceased for COVID-19 - Difference of mortality recorded in the considered period (from 24 February 2020 to 5 June 2020) - Credits: Department of Civil Protection - Presidency of the Council of Ministers. 
Figure 26d - Trend of the dead for COVID-19 - March-June 2020-2021

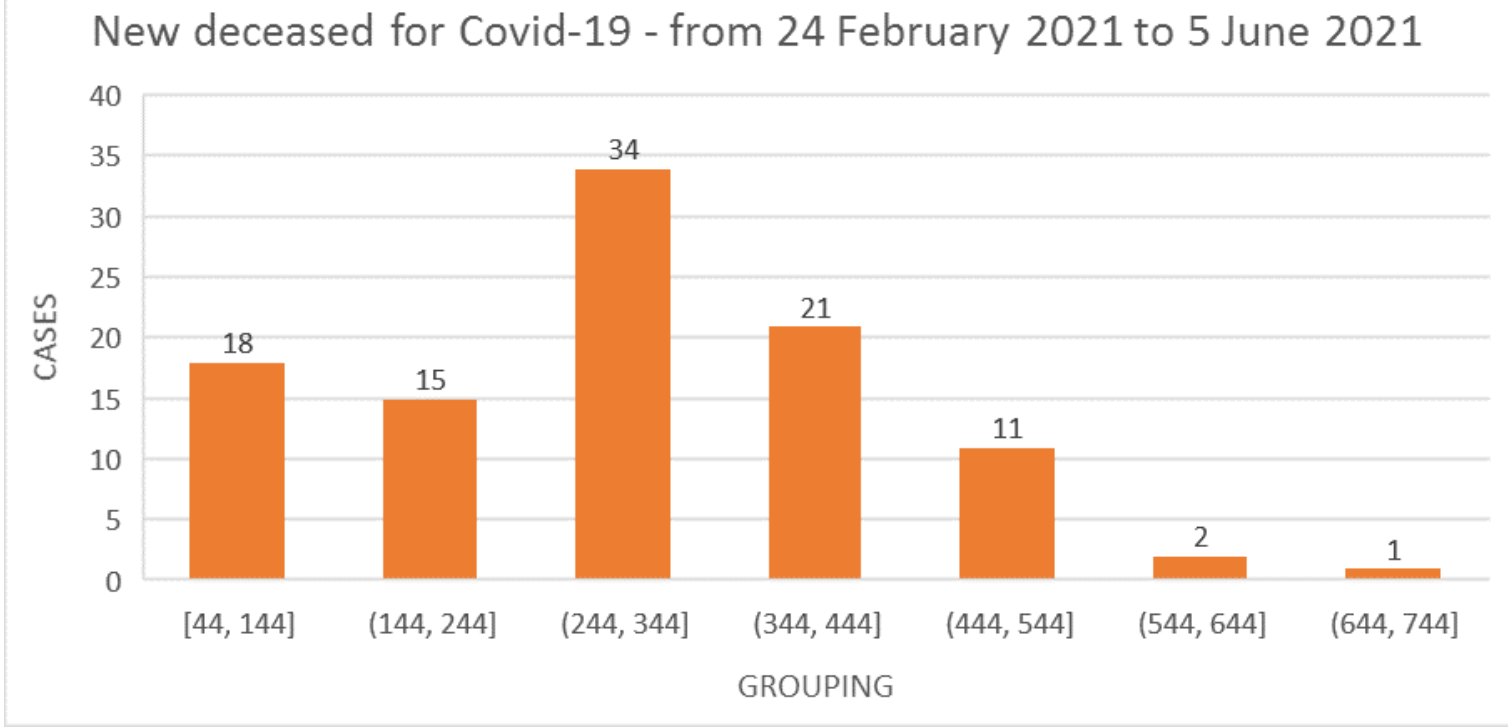

Fig. 26d - Grouping of the new deceased for COVID-19 - Difference of mortality recorded in the considered period (from 24 February 2021 to 5 June 2021) - Credits: Department of Civil Protection - Presidency of the Council of Ministers.

The two graphs (Fig. 26c e Fig. 26d), they also indicate that the greatest number of deaths took place in the 2020 period, with important peaks of more than 960 cases in one day.

Figure 27 - Electromagnetic emissions and their influence on microorganisms

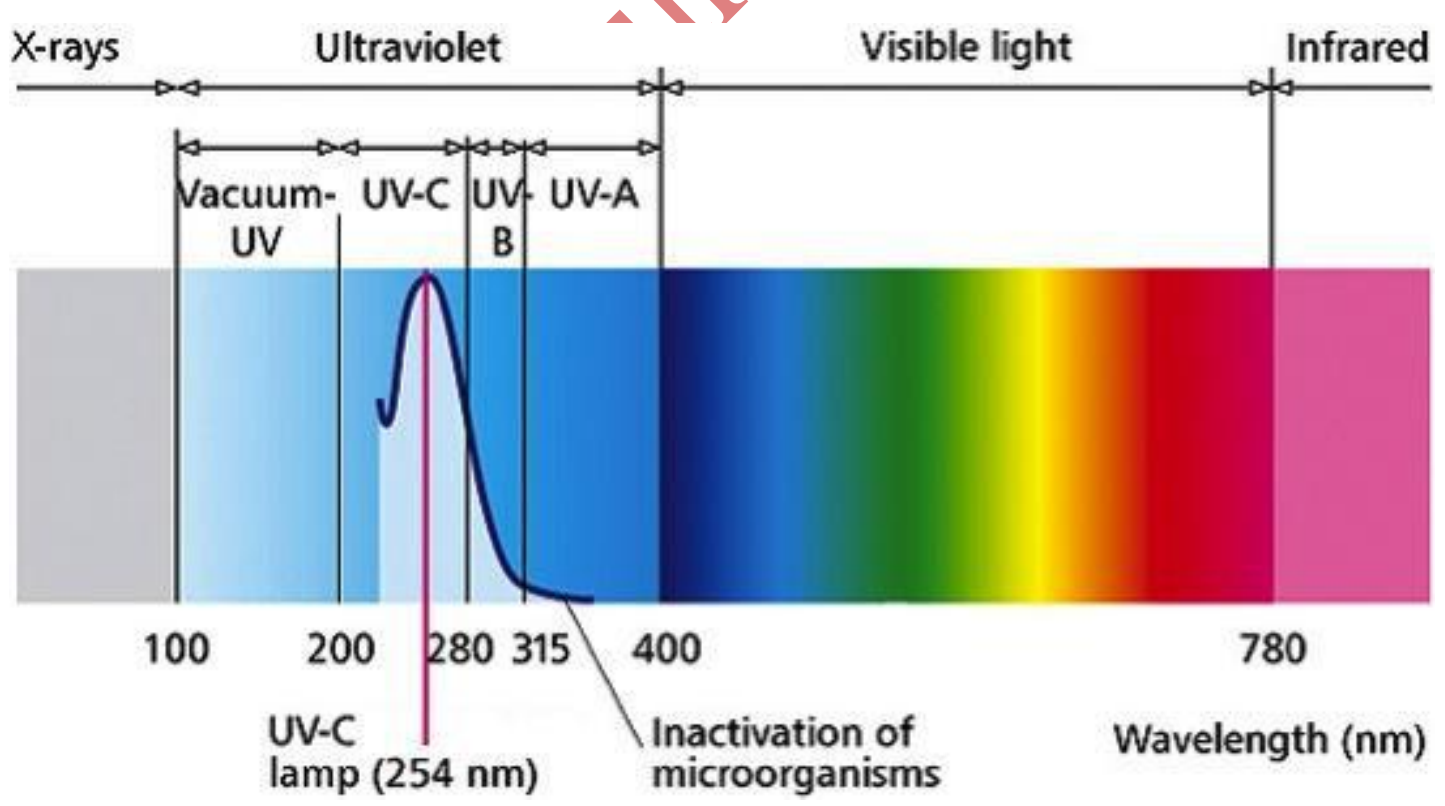

Fig. 27 - Schematization of electromagnetic emissions (solar), relative to both the visible spectrum from the human eye, and to the invisible one. In this case the infrared spectrum (on the right) and the ultraviolet (on the left). The greater effectiveness of the UV-C spectrum (ultraviolet) in determining inactivation and destruction of microorganisms, compared to other types of ultraviolet rays (UV-A and UV-B) is evident. 
and its replication since in the face of greater solar radiation, this goes to disappear almost totally, managing to infect with a capacity of dozens, hundreds or thousands of times less than the coldest periods of the year [23].

UV-C rays for example are almost completely filtered by the earth's atmosphere, while they are able to permeate UV-A and UV-B ultraviolet rays (as visible in the Fig. 28) which in any case have their effect on such microorganisms even more mildly.

The factors that can influence the antiviral activity of solar radiation are the following:

- Elevation of the sun with respect to the horizon (in the summer season the elevation is greater, while in the winter station the elevation is smaller).
- Angle of incidence of sunlight on the surface of the planet (in the summer season the angle of incidence is greater, compared to the winter season).

- Presence of Ionospheric Layers able to filter UV emissions.

- Presence of overcast sky and cloudiness, able to filter UV emissions and partly ionizing particles coming from space.

- Presence of obstacles able to shield sunlight (houses, trees, fixtures, etc.).

- More environmental temperature.

- Minor presence of moisture on the surfaces. Solar radiation is very important because its action on microorganisms and life forms is fundamental [48], especially in recent decades due to the known depth of the atmospheric ozone shield that ended up filtering ultraviolet rays, which have negatively influenced the entire world ecosystem.

Figure 28 - Typology of ultraviolet rays and their atmospheric Penetration

\section{UV rays}

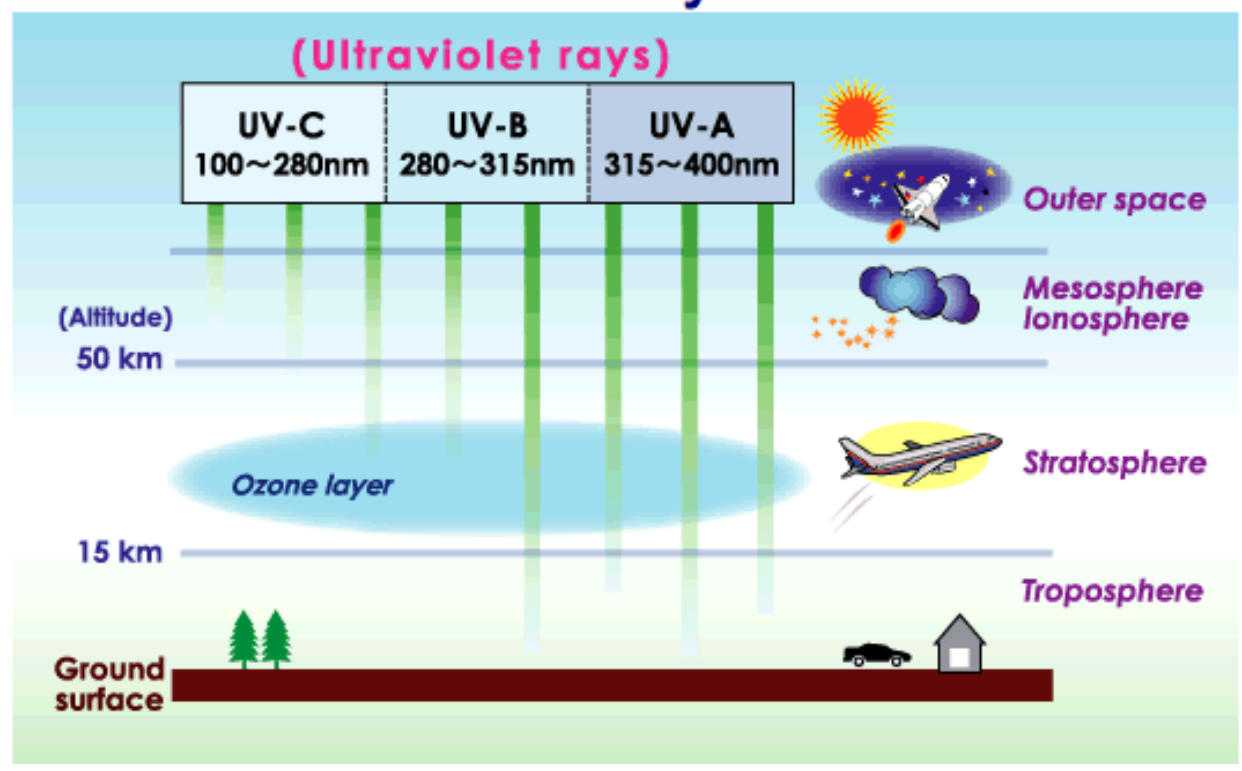

Fig. 28 - Penetration of UV rays of solar origin inside our atmosphere, based on the type of electromagnetic frequency. Credits: Center for Global Environmental Research, National Institute for Environmental Studies Japan.

It is desirable that in a future not too far away, the climate and natural potential is also considered, for the mitigation of viral infections and for the strategies linked to fighting epidemics and possible pandemics.

\section{1 - Life Cycle}

According to this data emerge, the graphs would actually evolve the evolution of the normal "life cycle" of the virus, a vital cycle that all living organisms
This is certainly important to make in a way of planning targeted, effective and efficient interventions against infections from harmful microorganisms for humans and animals.

possess, based on seasonality, in which living organisms are born, fibernate, grow And then they reproduce. A vital cycle that also the new coronavirus 
has.

The existence of increases and decreases of its vitality, which seem to not react in an absolute way to lockdowns shows how the statistical numbers referring to the life of the virus, are referred only to its vital cycle. This hypothesis is certainly not peregrine, but must be considered in a serious and innovative scientific environment, for the mitigation of its future diffusion, and as already mentioned, to manage the best resources for the care of infected patients. Not by chance the epidemic (sometimes pandemic) infection of Coronavirus is called "seasonal influence", precisely because the life cycle of these microorganisms makes them spread more during the coldest months [23].

\section{0 - CONCLUSION}

In conclusion, this study has tried to provide information on which to meditate in future strategic choices to dramatically reduce the capacity of infection of the new Coronavirus. The study unequivocally established that the virus seems to be sensitive to warm climate and greater solar radiation, during hot seasons, where a clear and rapid decrease of the virus action on a global scale is observed. If this were not the case, it would not explain why the virus's virus performance should be the same in every northern part of the earth's globe. It is obvious that the use of Individual Protection Devices (IPD) and the use of specific prophylaxis (drugs) on patients and healthcare personal at risk of infection can improve safety, decreasing the capacity of the virus to infect and / or To make it sick; But knowing the virus's life cycle, in proportion to the climate in which this is expressed, can certainly help consider more sensible strategic choices to combat infection and limit pandemic and epidemic on a global scale.

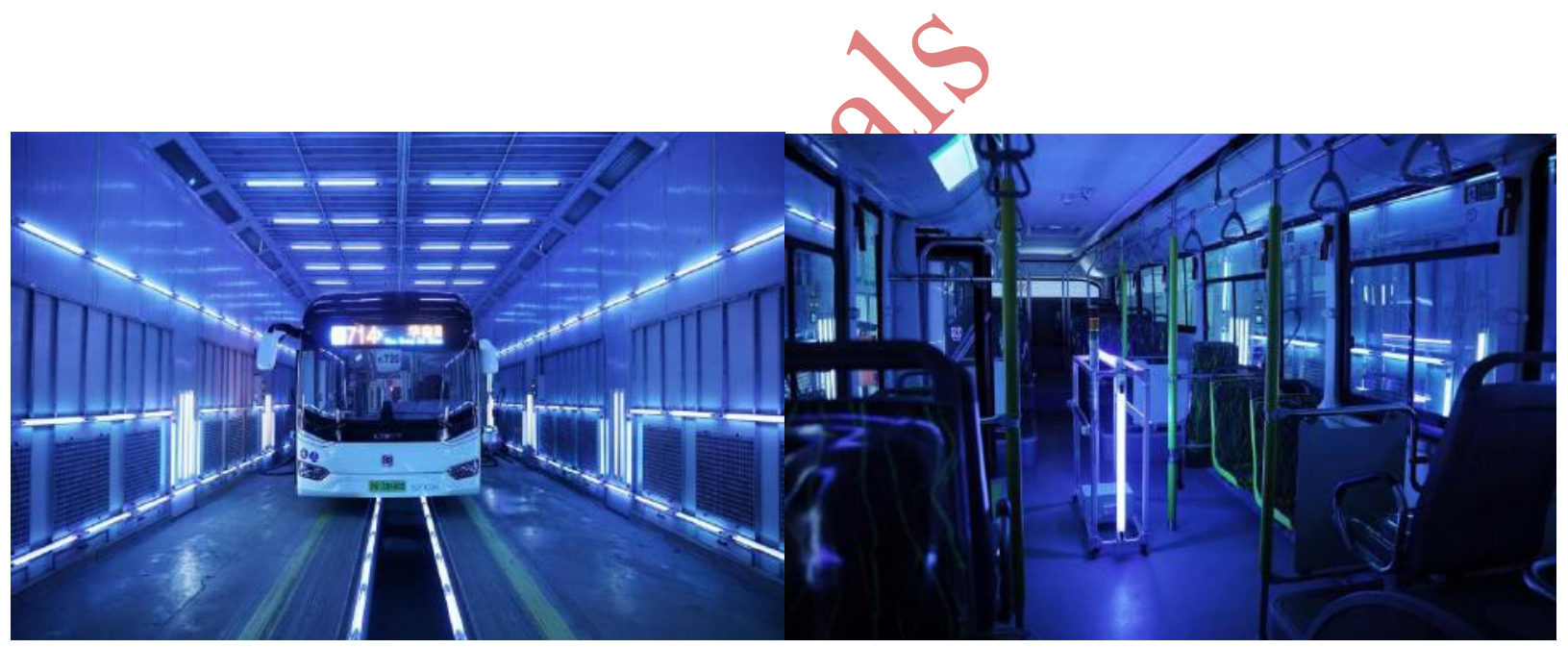

Fig. 29 - Bus disinfection through UV lights. A way to fight Coronavirus in Shanghai. Credits: https://www.sustainable-bus.com/news/busdisinfection-through-uv-lights-a-way-to-fight-

The use of UV-C lamps within the houses, hospitals, railway stations and public transport can positively affect the local epidemic of the new Coronavirus, decreasing its survival capacity and therefore infecting other healthy individuals [55]. A choice this that nobody in Italy has seriously considered.

The increase in environmental temperature has allowed our natural habitat to decrease the presence of the new Coronavirus in the environment in which we live, on

Fig. 30 - Bus disinfection through UV lights. A way to fight Coronavirus in Shanghai. Credits: https://www.sustainable-bus.com/news/busdisinfection-through-uv-lights-a-way-to-fight-

this forehead could be used for irradiation sources based on IR-infrared rays, able to determine a real obstacle to virus proliferation, especially in areas where this can accumulate (public places with high population).

What must be done is to consider strategies that imitate the natural environment, an environment that is unated alone is to limit the propagation of the new coronavirus, it is no coincidence that in China, the 
evolution of the pandemic has practically arrested already later The first wave of 2020 , because strategies are considered that incorporate the use of technologies already present in nature (Fig. 29 and 30)a choice this that nobody in Italy has seriously considered.

The increase in environmental temperature has allowed our natural habitat to decrease the presence of the new Coronavirus in the environment in which we live, on this forehead could be used for irradiation sources based on IR-infrared rays, able to determine a real obstacle to virus proliferation, especially in areas where this can accumulate (public places with high population).

What must be done is to consider strategies that imitate the natural environment, an environment that is unated alone is to limit the propagation of the new coronavirus, it is no coincidence that in China, the evolution of the pandemic has practically arrested already later The first wave of 2020 , because strategies are considered that incorporate the use of technologies already present in nature.

Change our lifestyle, to combat the new coronavirus infection, is essential for a population that wants to remain healthy. On this the studies are very precise. Exercise and physical activity, especially if aerobics, helps our respiratory system to remain efficient. Not only, being able to spend more hours under the sun, certainly helps the organism against virus infections. Staying at home, along with other people, without being able to carry out adequate physical activity, implementing our sedentaryity certainly does not help our body to stay healthy. In fact, there are at least three factors through which meteorological conditions can modulate viral transmission. The first of these factors

\section{1 - Solutions}

After analyzing the global pandemic trend and above all the national one (Italian), it was possible to hypothesize a series of solutions to be adopted in the immediate and in the near future, to mitigate the problem of the spread of the new Coronavirus (SARSCoV-2):

A. Greater physical activity during cold seasons.

B. Increased exhibition to sunlight on our body.

C. Expose to the sun of clothing, the shoes and blankets.

D. Expose to the sun the house in which we live, allow solar rays to enter also by diffraction or refraction within the home environment. Very useful is for example to be able to open the shutters to leave the glazing glazing from are human behavior. When the temperature is low, humans typically spend more time at home, with reduced social spacing and less ventilation than outdoors. For example, schools are places to improve influenza transmission, for intense internal activities. The second factor is the immune system of each of us which is susceptible [54]. The solar radiation guide changes in the human immune system modulating melatonin and / or vitamin D24-26 [54]. The last but it could be the most important factor is the survival of the virus, ie the virucid effect of UV rays (ultraviolet). The tests revealed that aerosols, as a means of transmission of the COVID-19, lead the virus to the surfaces, where it remains active for several hours per day. Intense solar radiation can inactivate the virus on the surface through the physical properties of the latter; the virus is induced to decrease its transmission capacity, if bombed with UV rays, while the thermal variation acts on its life cycle in a very intense way [54].

On this the science is now concorded. So in this case, the mitigation of the pandemic and endemic problem can be solved by taking sensible choices, in which human health must be placed at the center of the problem, and the health of the individual, thanks to physical activity and exposure of the our body in the sun, even in the winter periods where exposure to the sun is certainly lower to rehabilitate our immune defenses and to expose the viruses adherent to our garments, to the action of UV rays, thanks to direct sunlight (especially in the Heat hours). These are essential methodologies, now recognized at the scientific level for a long time, which also apply to the new Coronavirus responsible for COVID-19 [55] [56] [57].

which solar rays can then enter.

E. Use of emission lamps in the UV-C electromagnetic spectrum.

F. Use of emission lamps in the UV-A and UVB electromagnetic spectrum.

These solutions are to be added to the basic standards that can be used to combat the spread of viruses, such as the use of chlorine-based detergents, use of disposable protective gloves, use of handkerchiefs in disposable paper, frequent washing of the hands, Disinfection of home surfaces and social spacing in closed and restricted places.

The use of surgical masks within closed environments does not provide any protection against the propagation of the new coronavirus, for this you need 
to use filter masks.

G. Provide the FFP-2 and FFP-3 masks population, withdrawing the surgical ones which have no filtering function.

In fact, it is not included, as ever Italian policies have obliged the use of non-filtering masks on the population, masks that do not allow you to filter anything. Reason for the enormous spread of the new coronavirus in public environments, it could in fact have been determined also by the use of Individual Protection Devices (IPD) not suitable. the spread of the virus, especially united to the disinfection of the hands with hydro-alcohol gel, used from the first weeks of the confirmed Pandemic.

H. Specific policies to allow the purchase (lower cost) of the IPD, by the population, especially the least the least.

Many have been the wrong policies in Italy, who have not considered for example use "for all", of filtering masks, at an affordable price, instead of spreading, as happened, surgical masks whose filtering capacity is practically nothing.

The use of filtering masks of type FFP-2 and FFP-3 by the population, would probably be allowed to decrease

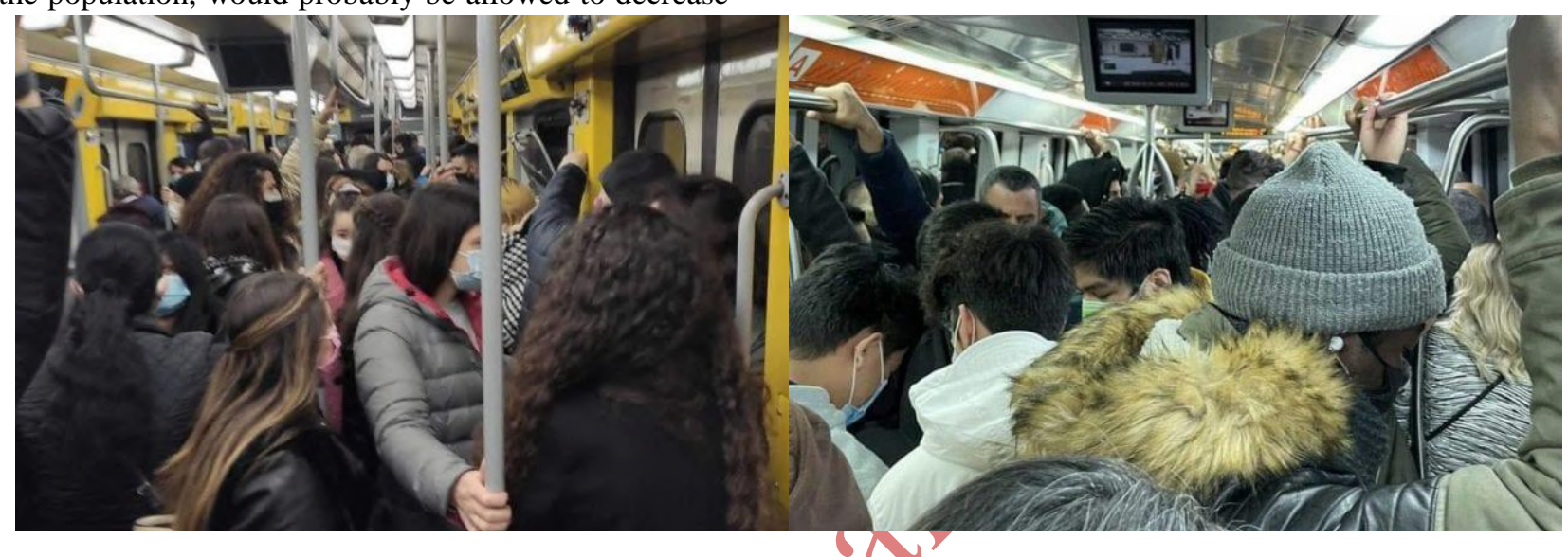

Fig. 31 - Metro " 1 " of Naples, Italy: the high number of people present inside the railway wagon is observed, while people use only surgical or selfbuilt masks, whose filtering capacity is nothing. If you were used suitable IPD, probably the infection clusters would have been much less. Credits:
Fig. 32 - Metro "A" of Rome (between Manzoni and Anagnina), Italy: the high number of people in the railway wagon is observed, while people use only surgical or self-built masks, whose filtering capacity is nothing. If you were used suitable IPD, probably the infection clusters would have been much less. Credits: Fanpage.

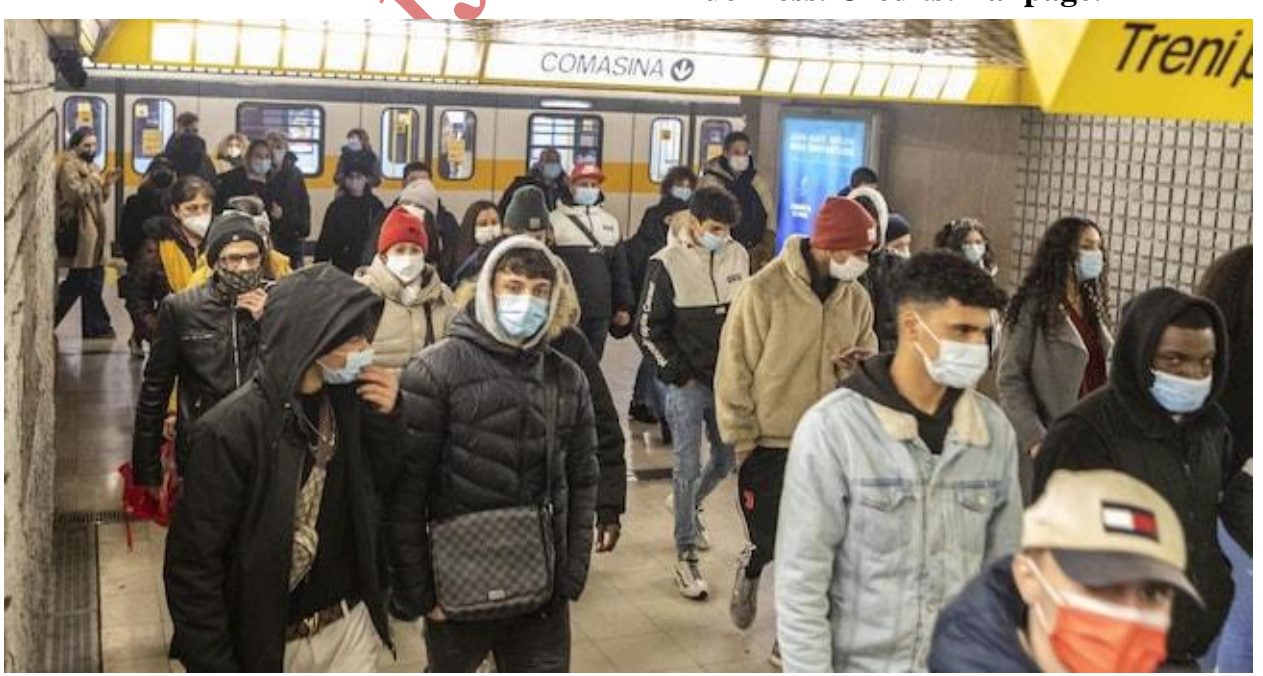

Fig. 33 - Metro of Milan, Italy. The presence of travelers who use only surgical or self-built masks, from an example of how the pandemic problem has been addressed in Italy, allowing the population to use IPD not suitable in environments at risk of the new Coronavirus transmission. Credits: imagoeconomica. 
The use of these solutions would certainly be allowed not only a lowering of the number of infections, but also a non-account monetary savings, since it could have influenced the containment of the virus by acting on the use of suitable IPD especially in public environments (Metropolitan stations, railway stations, airport areas), in the workplace, and even in a home

\subsection{An invitation to reflection}

In conclusion, this study invites doctors, health personnel, local and international leaders, politicians and authorities, as well as other researchers to meditate on this aspect of the pandemic question, still little considered. Invite them to consider strategies for containing viral epidemics based on the exploitation of the natural climate and on some features of the latter that can be artificially reproduced to make the life of the new coronavirus more difficult; In addition to the adoption suitable for certain political choices.

It is still meant that in this new millennium, it still decides to face health problems without a wide vision of the problem and without considering all the hypotheses of care, linked to aspects that it is possible to mitigate influencing on simple technologies and to everyone's reach, In addition to adequate physical activity, to a sufficient solar exposure, which is part of a normal life context in healthy populations.

Science and medicine must be able to mitigate the problem of viral infections, especially to all those dangerous viruses, such as the SARS-COV-2, to therefore allow the population of not infecting, and not, as too often is observed, facing The problem only

\section{REFERENCE}

1. Dati delle infezioni del nuovo coronavirus Dipartimento della Protezione Civile italiana https://opendatadpc.maps.arcgis.com/apps/das hboards.

2. Dopo la malattia anche il coronavirus ha un nome, Sars-CoV-2, in ANSA, 12 febbraio 2020.

http://www.ansa.it/canale_scienza_tecnica/not izie/biotech/2020/02/12/dopo-la-malattia-

anche-il-coronavirus-ha-un-nome-sars-cov-2-

_827d301b-9dfa-441a-a734-

a00e1aef0777.html.

3. Che cosa è il coronavirus, in Agenzia Giornalistica Italia, 7 marzo 2020. URL consultato il 18 luglio 2020. https://www.agi.it/salute/news/2020-03- context (an example are images from Naples, Rome and Milan (Fig. 31, 32 and Fig. 33).

In these places, no disinfection or enough protection means were also distributed (such as hydro-alcohol gel or disposable gloves), which have scarceed within the places of passage and stopping people, with obvious risks for the Human transmission of the SARS-CoV-2.

once the population is infected or ill. This must be the purpose of science and medicine. We must not limit us to administer drugs, the action of medicine and its responsibility in this context must start much earlier.

Thanks: I thank my colleagues, doctors and all the health personnel who in these terrible months have taken care of and assisted patients suffering from COVID-19, within the infectious isolation wards, working constantly and giving up part of their life, risking it at times. I thank them all. My hope is that future policies can consider even more the value of human life, recognizing the importance of ethics and values, as a fundamental requirement for the evolution of a concept of health that is effectively the mirror of what everyone we would like. Today we live in a beautiful country called Italy, which the whole world envies us and looks at with admiration, the world looks at us and expects concrete and serious answers from all of us for the future of healthcare not only in Italy but in the world. It is really worth working to ensure that the value of life can be respected, it is worth the risk for this value that has no equal... I therefore hope that our future choices can consider all this. 07/coronavirus-cosa-sapere-7372429/.

4. L'OMS ha chiamato COVID-19 la sindrome causata dal nuovo coronavirus, in il Post, 11 febbraio 2020. URL consultato l'11 febbraio 2020 (archiviato l'11 febbraio 2020). https://www.ilpost.it/2020/02/11/covid-19nome-sindrome-nuovo-coronavirus-oms/.

5. Novel Coronavirus (2019-nCoV) Situation Report - 10 (PDF), OMS - Organizzazione Mondiale della Sanità, 30 gennaio 2020. URL consultato il 18 luglio 2020. https://www.who.int/docs/defaultsource/coronaviruse/situationreports/20200130-sitrep-10-ncov.pdf.

6. New-type coronavirus causes pneumonia in Wuhan: expert, su Xinhua, 9 gennaio 2020. 
URL consultato il 23 gennaio 2020. http://www.xinhuanet.com/english/202001/09/c_138690570.htm.

7. http://www.chinacdc.cn/dfdt/201912/t201912 26_209404.html.

8. https://platform.gisaid.org/epi3/start/CoV202 0 .

9. https://bnonews.com/index.php/2020/01/timel ine-coronavirus-epidemic/.

10. Erika Edwards, How does coronavirus spread?

https://www.nbcnews.com/health/healthnews/how-does-new-coronavirus-spreadn1121856.

11. CDC, How 2019-nCoV Spreads, su cdc.gov. URL consultato il $1^{\circ}$ febbraio 2020 https://www.cdc.gov/coronavirus/2019ncov/about/transmission.html.

12. Tina Hesman Saey, How the new coronavirus stacks up against SARS and MERS, su sciencenews.org, 24 gennaio 2020. URL consultato il 25 gennaio 2020 (archiviato dall'url originale il 25 gennaio 2020).

13. L'epidemiologia per la sanità pubblica Istituto Superiore di Sanità https://www.epicentro.iss.it/coronavirus/cosa-sono.

14. Giovanni Agnesod (3), Mario Dionisi (1), Margherita Falcone (1), Sonia Fontani (1), Leandro Magro (1), Giuseppe Menna (1), Rita Ocone (1), Daniela Parisi (1), Carmelina Salierno (1), Francesco Salvi (1), Roberto Sogni (2), Anna Maria Sotgiu (1), Giancarlo Torri (1), Paolo Zeppa(1), Joanne Wells (1) Curatore: Silvia Iaccarino (1) - Referente: Giancarlo Torri (1) - 1) Apat, 2) Arpa Emilia Romagna, 3) ARPA Valle d'Aosta Radiazioni Ionizzanti, Annuario Dei Dati Ambientali, Capitolo $11 \quad$ https://annuario.isprambiente.it/sites/default/fi les/-pdf/2005-2006/versione_integrale/Radiazioni\%20ionizzanti.pdf.

15. Ispettorato federale della sicurezza nucleare IFSN Confederazione Svizzera - Serie sulla radioprotezione: effetti biologici delle radiazioni ionizzanti - https://www.ensi.ch/.

16. Università degli Studi di Palermo - Effetti Biologici delle radiazioni - Dr. Francesco Di Rosa - Dirigente Fisico https://www.asp.cl.it/upload/asp_cl_ecm10/ge stionedocumentale/39_-

Effetti_Biologici_Radiazioni_784_79551.pdf.

17. Radon e cancro al polmone - Lega Polmonare Svizzera - Ufficio federale della sanità pubblica UFSP, divisione Radioprotezione, sezione Rischi

radiologici.

https://www.liguepulmo-

naire.ch/uploads/tx_pubshop/Foglio_informat ivo_Radon_e_cancro_ai_polmoni.pdf.

18. Lega Contro il Cancro - Ufficio federale della sanità pubblica - Divisione radioprotezione

19. Sezione Rischi radiologici https://www.legacancro.ch/prevenire-ilcancro/prevenzione-e-diagnosiprecoce/diagnosi-precoce/prevenzione-ediagnosi-precoce-del-cancro-del-polmo-ne/dl-/fileadmin/downloads/sheets/foglioinformativo-sulla-radon-034102901121.pdf.

20. Jonathan D. Cherry,Bin Liu,Jeffrey L. Frost,Cynthia A. Lemere,Jacqueline P. Williams,John A. Olschowka - Galactic Cosmic Radiation Leads to Cognitive Impairment and Increased $\mathrm{A} \beta$ Plaque Accumulation in a Mouse Model of Alzheimer's Disease - Plos One - December 31 ,

2012https://doi.org/10.1371/journal.pone.005 3275 - https://journals.plos.org/plosone/article?id=10.1371/journal.pone. 0053275 .

21. What happens to your brain on the way to Mars - Vipan K. Parihar1, Barrett Allen1, Katherine K. Tran1, Trisha G. Macaraeg1, Esther M. Chu1, Stephanie F. Kwok1, Nicole N. Chmielewski1, Brianna M. Craver1, Janet E. Baulch1, Munjal M. Acharya1, Francis A. Cucinotta2 and Charles L. Limoli1 - Science Advances 01 May 2015: Vol. 1, no. 4, e1400256 - DOI: 10.1126/sciadv.1400256.

22. J. G. Calvert - Glossary of atmospheric chemistry terms (Recommendations 1990) De Gruyter | Published online: January 1, 2009 - International Union of pure and applied chemistry applied chemistry division commission on atmospheric chemistry Atmospheric Chemistry Division National Center for Atmospheric Research, Box 3000, Boulder, CO 80307, USA. https://www.degruyter.com/document/doi/10. 1351/pac199062112167/html.

23. L'epidemiologia per la sanità pubblica Istituto Superiore di Sanità (ISS). https://www.epicentro.iss.it/influenza/influenz a.

24. INAIL, Contaminazione Fungina in ambienti indoor: Rischi per la salute occupazionale (2017).

25. HARM, W., 1980, Biological Effects of Ultraviolet Radiation, International Union of Pure and Applied Biophysics, Biophysics series, Cambridge University Press. 
26. Federal Energy Management Program, "Fact Sheet," for U.S. Department of Energy Efficiency and Renewable Energy, May 2005.

27. I metodi di sanificazione e bonifica: efficacia, vantaggi e svantaggi Dr. Roberto Cagarelli, 2011 (servizio Sanità Pubblica Emilia Romagna).

28. J. Siegel, et. al., "Dirty Air Conditioners: Energy Implications on Coil Fouling," 2002.

29. Air Conditioning Heating Refrigeration. "UVC Lights Keep Hospital Cool, Efficient" The News, Sep 2007.

30. American Society of Heating Refrigerating and Air-Conditioning Engineers, INC. ASHRAE Handbook: HVAC Systems and Equipment, 2008; Chapter 16 - Ultraviolet Lamp Systems.

31. American Society of Heating Refrigerating and Air-Conditioning Engineers, INC. ASHRAE Handbook: HVAC Applications (SI), 2011; Chapter 60 - Ultraviolet Air and Surface Treatment.

32. BCA (Building \& Construction Authority). Green Building Design Guide - AirConditioned Buildings.

33. Environmental Protection Agency. Fact Sheet: Ventilation and Air Quality in Offices. Indoor Environments Division Document ID: EPA 402-F-94-003.

34. Foarde, K., D. Franke, T. Webber, J. Hanley, K. Owen and E. Koglin. Technology Evaluation Report: Biological Inactivation Efficiency by HVAC In-Duct Ultraviolet Light Systems - Steril-Aire, Inc. Model SE 1 VO with GTS 24 VO Emitter, 2006. EPA, Office of Research and Development, National Homeland Security Research Center.

35. Keikavousi, F. UVC: Florida Hospital Puts HVAC Maintenance Under A New Light, Engineered Systems, March 2004.

36. Kowalski, W. J. and W. Bahnfleth. Airborne Respiratory Diseases and Mechanical Systems for Control of Microbes Heating/Piping/Air Conditioning, July 1998, 34-48.

37. Montgomery, R. and R. Baker. Study Verifies Coil Cleaning Saves Energy. ASHRAE Journal 2006 48(11), 34-36.

38. National University of Singapore. Sustainability.

39. Penton Media Inc. SCACD: UVC Lights Enhance IAQ, Reduce AHU Operating Costs, 1998.

40. Scheir, R. Putting UVC in a New Light. RSES Journal, March 2008.
41. Scheir, R. The HVAC Factor: The ABCs of UVC, Today's Facility Manager, August 2009.

42. Stoecker, W. F., Jones, J.W. Refrigeration \& Air Conditioning, McGraw Hill, N.Y., 1986.

43. Steril-Aire Inc. American Electric Power: How Do Utilities Save Energy? With "UVC for HVAC".

44. U.S. General Services Administration. 2005. PBS-P100, 8. Facilities Standards for the Public Buildings Service.

45. U.S. Department of Health and Human Services/Centers for 9. Disease Control and Prevention. 2005. "Guidelines for preventing the transmission of Mycobacterium tuberculosis in health-care settings, 2005." Morbidity and Mortality Weekly Report 54.

46. U.S. Department of Homeland Security/Federal Emergency 10. Management Agency. 2003. FEMA 426, Reference Manual to Mitigate Potential Terrorist Attacks Against Buildings.

47. U.S. Environmental Protection Agency. 2007. EPA 600/R-07/157, 11. Building Retrofits for Increased Protection Against Airborne Chemical and Biological Releases.

48. Arun K. Shanker - Countering UV-B stress in plants: Does selenium have a role? National Research Centre for Agroforestry, Pahuj Dam, Gwalior Road, 284003, Jhansi, Uttar Pradesh, India - Corresponding author* Received 9 November 2005. Accepted in revised form 16 November 2005. Plant and Soil (2006) 282:21-26 - Ó Springer 2006DOI 10.1007/s11104-005-5249-x.

49. Jose-Luis Sagripanti 1, C David Lytle Inactivation of influenza virus by solar radiation - Photochemistry and Photobiology PMID: 17880524 DOI: 10.1111/j.17511097.2007.00177.x - Issue Online: 26 July 2007, Version of Record online:26 July 2007, Editorial history: Received 3 April 2007; Accepted 24 May 2007 https://onlinelibrary.wiley.com/doi/abs/10.111 1/j.1751-1097.2007.00177.x.

50. C. David Lytle and Jose-Luis Sagripanti Predicted Inactivation of Viruses of Relevance to Biodefense by Solar Radiation Journal of Virology - J Virol. 2005 Nov; 79(22): 14244-14252 - doi: 10.1128/JVI.79.22.14244-14252.2005 PMCID: PMC1280232 - PMID: 16254359 https://www.ncbi.nlm.nih.gov/pmc/articles/P MC1280232/.

51. Jose-Luis Sagripanti, C. David Lytle - 
Estimated Inactivation of Coronaviruses by Solar Rad - iation With Special Reference to COVID-19 - Photochemistry and Photobiology - First published: 05 June 2020 - https://doi.org/10.1111/php.13293.

52. Mohammad Hossein Nasirpour, Abbas Sharifi, Mohsen Ahmadi \& Saeid Jafarzadeh Ghoushchi - Revealing the relationship between solar activity and COVID-19 and forecasting of possible future viruses using multi-step autoregression (MSAR) - Springer - Environmental Science and Pollution Research (2021) - Published: 16 March 2021. https://link.springer.com/article/10.1007/s113 56-021-13249-2.

53. Mohammad Hossein Nasirpour, Abbas Sharifi, Mohsen Ahmadi \& Saeid Jafarzadeh Ghoushchi - Revealing the relationship between solar activity and COVID-19 and forecasting of possible future viruses using multi-step autoregression (MSAR) - Springer - Environmental Science and Pollution Research (2021) - Published: 16 March 2021. https://link.springer.com/article/10.1007/s113 56-021-13249-2.

54. Maosheng He, Keyan Fang, Feifei Zhou, Tinghai Ou, Deliang Chen - A delayed modulation of solar radiation on the COVID19 transmission reflects an incubation period MedRxiv - The preprint server for Health Sciences - BMJ - Yale - Cold Spring Harbor
Laboratory - CSH. Posted October 14, 2020 https://www.medrxiv.org/content/10.1101/20 20.10.13.20183-111v1.

55. Ultraviolet light vs. COVID19: from the Sun to artificial lamps the germicidal power of ultraviolet rays against the pandemic - INAF Istituto Nazionale di Astrofisica http://www.inaf.it/en/inaf-news/uv-vscovid19\#null.

56. Fabrizio Nicastro, Giorgia Sironi, Elio Antonello, Andrea Bianco, Mara Biasin, John R. Brucato, Ilaria Ermolli, Giovanni Pareschi, Marta Salvati, Paolo Tozzi, Daria Trabattoni, Mario Clerici - Modulation of COVID-19 Epidemiology by UV-B and -A Photons from the Sun - medRxiv - BMJ - Yale - Cold Spring Harbor Laboratory - CSH - doi: https://doi.org/10.1101/2020.06.03.20121392 - Posted June 05, 2020.

57. Andrea Bianco, Mara Biasin, Giovanni Pareschi, dalberto Cavalieri, Claudia Cavatorta, Claudio Fenizia, Paola Galli, Luigi Lessio, Manuela Lualdi, Edoardo Redaelli, Irma Saulle, Daria Trabattoni, Alessio Zanutta, Mario Clerici - UV-C irradiation is highly effective in inactivating and inhibiting SARS-CoV-2 replication - medRxiv - BMJ Yale - Cold Spring Harbor Laboratory - CSH - doi: https://doi.org/10.1101/2020.06.05.20123463

- Posted June 07, 2020.

